Utah State University

DigitalCommons@USU

$12-2017$

\title{
Acculturation and Language Use in Intimate and Sexual Relationships Among Chinese Bilinguals
}

Tianyi Xie

Utah State University

Follow this and additional works at: https://digitalcommons.usu.edu/etd

Part of the Psychology Commons

\section{Recommended Citation}

Xie, Tianyi, "Acculturation and Language Use in Intimate and Sexual Relationships Among Chinese Bilinguals" (2017). All Graduate Theses and Dissertations. 6713.

https://digitalcommons.usu.edu/etd/6713

This Thesis is brought to you for free and open access by the Graduate Studies at DigitalCommons@USU. It has been accepted for inclusion in All Graduate Theses and Dissertations by an authorized administrator of DigitalCommons@USU. For more information, please contact digitalcommons@usu.edu.

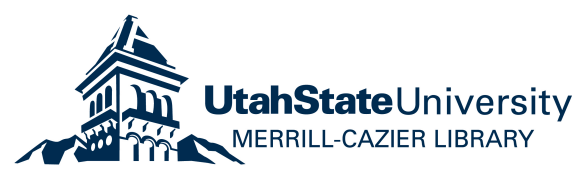


ACCULTURATION AND LANGUAGE USE IN INTIMATE AND SEXUAL

RELATIONSHIPS AMONG CHINESE BILINGUALS

by

\section{Tianyi Xie}

A thesis submitted in partial fulfillment

of the requirements for the degree

$$
\text { of }
$$

\section{MASTER OF SCIENCE}

in

Psychology

Approved:

Renee V. Galliher, Ph.D.

Major Professor

Rebecca K. Blais, Ph.D.

Committee Member
Melanie M. Domenech Rodríguez, Ph.D. Committee Member

Mark R. McLellan, Ph.D.

Vice President for Research and

Dean of the School of Graduate Studies

UTAH STATE UNIVERSITY

Logan, Utah 
Copyright (C) Tianyi Xie 2017

All Rights Reserved 


\author{
ABSTRACT \\ Among Chinese Bilinguals \\ by \\ Tianyi Xie, Master of Science \\ Utah State University, 2017
}

Acculturation and Language Use in Intimate and Sexual Relationships

Major Professor: Renee V. Galliher, Ph.D.

Department: Psychology

Chinese bilingual individuals in the U.S. navigate complex cultural contexts as they are exposed to potentially conflicting sets of values from American mainstream and Chinese cultures. Chinese and American values on sexuality and gender roles are mostly contradictory or conflicting, which may lead to increased acculturation distress and relationship strain in Chinese bilinguals. Less acculturated Asian American youth experience lower sexual self-efficacy and sexual satisfaction, and greater adherence to traditional gender roles. Recent studies suggested that language activates corresponding cultural mindset, which influences cognition, emotion, and behavior. The current study explores the ethnic identity and acculturation experiences of bilingual individuals of Chinese descent living in the U.S., along with their engagement with English and Chinese language in sexual and romantic relationships.

Chinese bilingual young adults in the U.S. $(n=190)$ completed a set of measurements online that included demographic and relationship history information, the 
Vancouver Index of Acculturation, Bicultural Identity Integration, Hurlbert Index of Sexual Assertiveness, Sexual Double Standard Scale, Dyadic Sexual Communication Scale, and a language preference inventory.

After controlling for covariates and other acculturation factors, bicultural identity conflict was consistently associated with sexual assertiveness, $F(5,65)=3.29, p=.01$, double sexual standard, $F(5,69)=16.24, p<.001$, and sexual communication, $F(5,71)=$ $17.23, p<.001$, in men. Language preference was associated with sexual assertiveness, $F(5,52)=2.99, p<.02$, and sexual communication, $F(5,63)=3.85, p=.004$, in women, but with sexual double standard and sexual communication in men. Furthermore, analysis of open ended responses suggested that language proficiency was the best predictor of language preference regardless of the context or the topics. Perceptions of the efficiency of the language depended on proficiency, especially for expressing positive emotions and making decisions as a couple. However, English was considered to have clearer labels for negative emotion, whereas Chinese was reported to convey stronger negative emotion. In addition, English was more comfortable to use for sexual communication because Chinese, in general, lacks sexual vocabulary. The current study has implications for culturally modifying sexual education for Chinese bilinguals in the U.S. 
PUBLIC ABSTRACT

Acculturation and Language Use in Intimate and Sexual Relationships Among Chinese Bilinguals

by

\section{Tianyi Xie}

People of Chinese heritage often face complex challenges because of the conflicting values from China and America, especially on sexuality. Through two thousand years of socialization, Chinese culture grew to endorse conservative sexual values and gender roles. In traditional Chinese culture, women are expected to remain chaste and play submissive roles in marriage. Sexuality is treated as a taboo topic that should not be discussed directly. Asian American youth who endorse less traditional Chinese values experience lower sexual satisfaction, lower confidence in their own abilities, and higher adherence to traditional gender roles. Language has also been found to potentially influence how people engage in sexuality by triggering a mindset of Chinese or English culture background.

The current study assessed ethnic identity and acculturation experiences as correlates of sexual and intimate interactions with partners among people with Chinese heritage, and how English and Chinese language are used in relationships. For men, more endorsement of traditional Chinese and mainstream American culture was associated with greater feelings of conflict in their cultural identity. Greater feelings of identity 
conflict linked to lower ability to effectively and assertively communicate with a partner on sexual topics. Men with higher feelings of identity conflict also reported higher double sexual standard. Women, on the other hand, did not report increased feelings of conflict as they endorsed Chinese and American cultures more strongly. Women's preference for English language was related to their ability to effectively and assertively communicate with partner on sexual topics, whereas men's preference for English language was related to greater communication with partner and lower double sexual standard. Moreover, language fluency was the strongest indicator of language preferences regardless of the contexts or the topics. When making decisions or expressing positive feelings to partner, participants considered a language more effective when they are more fluent in it. However, when expressing negative emotion or discussing sexual topic with partner, people tended to prefer English because English has clearer labels for emotions and sexual terms.

In sum, cultural identity, acculturation experiences, and language proficiency all related to Chinese bilinguals' sexual and romantic attitudes and behaviors, although unique patterns emerged for men and women. 


\section{ACKNOWLEDGMENTS}

First of all, I would like to thank my chair, Dr. Renée V. Galliher, for supporting and guiding me through this project with great patience and kindness. I would also like to thank my committee members, Dr. Melanie Domenech Rodríguez and Dr. Rebecca K. Blais, for their thoughtful inputs and constant encouragements. It has been a challenging but wonderful journey, and I could not make it without all of your care, compassion, and support.

Special thanks go to my better half, Weijiu, whom has always been there for me and helped me through every difficulty with his love and wisdom. I would like to thank my family and friends back in China for their distant but infinite support and love.

Tianyi Xie 


\section{CONTENTS}

\section{Page}

ABSTRACT

iii

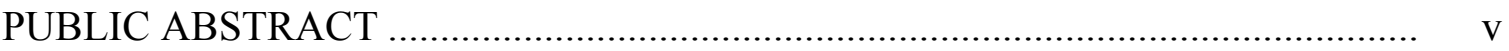

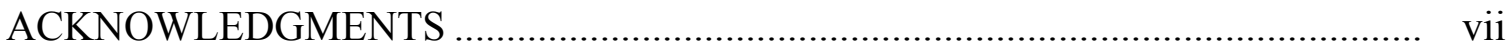

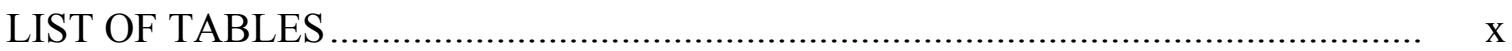

\section{CHAPTER}

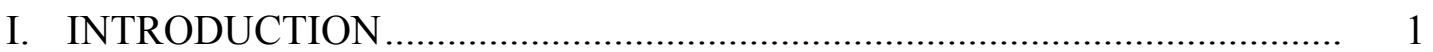

II. REVIEW OF LITERATURE................................................................. 5

Cultural Context ......................................................................................... 5

Acculturation Among Asian American Young Adults ................................ 12

Language Priming and Cultural Mindset .................................................. 19

Summary and Research Questions ....................................................... 25

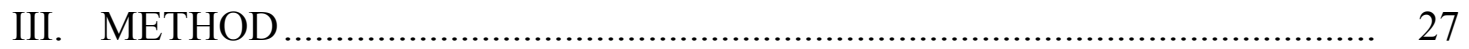

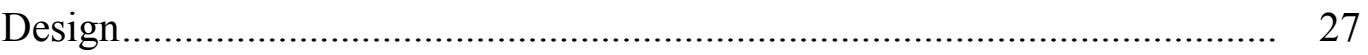

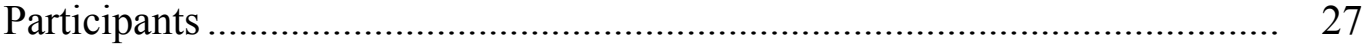

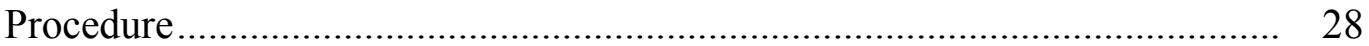

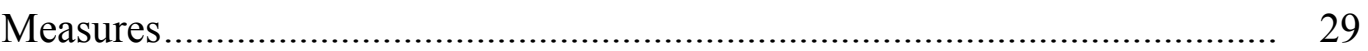

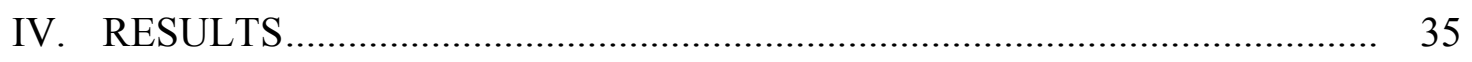

Descriptive Statistics ............................................................................. 35

Review of Open Ended Descriptions of Language Use ............................ 42

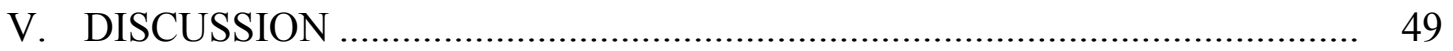

Description of Language, Cultural, and Sexual Variables ......................... 50

Relationships Between Cultural and Sexual Variables ................................ 52

Open-Ended Questions.................................................................. 55

Summary and Limitations ................................................................. 56

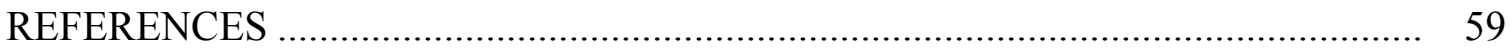




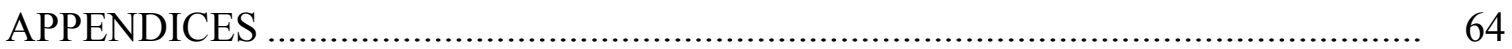

Appendix A: Informed Consent......................................................... 65

Appendix B: Measures .................................................................... 68 


\section{LIST OF TABLES}

Table

1. Descriptive Statistics for Cultural and Sexual Variables .............................. 35

2. Frequencies for Romantic Relationship Variables ................................... 36

3. Bivariate Correlations among Cultural variables and Sexual Variables for Woman and Men................................................................................. 38

4. Regression of Acculturation, Language Preference, and Covariates on Sexual Assertiveness Among Women and Men ........................................... 39

5. Regression of Acculturation, Language Preference, and Covariates on Sexual Double Standard Among Women and Men....

6. Regression of Acculturation, Language Preference, and Covariates on Sexual Communication Among Women and Men ..................................... 41

7. Qualitative Results of Language Preferences Open-Ended Questions ............. 44 


\section{CHAPTER I}

\section{INTRODUCTION}

The population of those who identify as Asian was the fastest growing racial/ ethnic group in the U.S. from 2000 to 2010 with an increase of 43\% (Hoeffel, Rastogi, Kim, \& Shahid, 2012). Chinese (including Taiwanese) was reported as the largest ethnic group within the Asian population in the U.S. The modern wave of Asian immigration started about 50 years ago, and in 2013, Asians became the largest new immigrant group to the U.S. (Pew Research Center, 2013). Many Asian immigrants are motivated by educational and/or career opportunities. More than half of visiting scholars and international students come from Asia for higher education in the U.S. (Institute of International Education, 2014) and 31\% of them are from China. Chinese who live in the U.S. have different immigration generations and residence duration, which may result in a range of acculturation levels.

Acculturation is defined as the adaptation process to a new culture when two distinct groups come to contact with each other for a long period of time (Berry, 2003). Cultural groups can be very similar or dissimilar across different dimensions of values, beliefs, and practices. Dissimilarities can cause particular stressors in the process of acculturating or accommodating to a new host culture. Chinese and American values on sexuality and gender roles are mostly incompatible and conflicting, which poses a challenge for Chinese young adults trying to navigate through two cultures and develop their own attitudes and beliefs towards sexual and intimate relationships. Traditional sexual values and gender roles have been endorsed and reinforced in China for over two 
thousand years (Ruan, 1991; Woo, 2016). Although there were periods of time when restrictions on women's activities were relatively loose, the popularity of Buddhism and the emergence of religious Daoism in Tang Dynasty, and the Song government's endorsement of Neo-Confucianism ultimately determined the overall trend of increasingly limiting the female role to solely serving parents, in-laws, husbands, and sons. Neo-Confucianism has been widely adopted in East Asian cultures and contributed to various sexual and gender double standards between women and men (Brotto, Chik, Ryder, Gorzalka, \& Seal, 2005; H. Kim, Edwards, Sweeney, \& Wetchler, 2012; J. L. Kim \& Ward, 2007; Lee \& Mock, 2005; Meston, Trapnell, \& Gorzalke, 1998; Tong, 2013; Woo, 2016; Woo \& Brotto, 2008; Youn, 2001). American sexual norms and values have also historically placed restrictions on female sexuality and suppressed sexual desire, but more liberal views on sexuality and gender equality shifted the social norm in 1960s, contributing to increasing openness to sexuality in North America in the past few decades (Dabhoiwala, 2012; Garlick, 2011; McNair, 2002; Robinson, Ziss, Ganza, \& Katz, 1991). Acculturation can be measured with either a unidimensional model that often uses a proxy such as the length of residency for acculturation, or preferably, bidimensional models that independently assess individuals' endorsements of U.S. mainstream and heritage cultures. Previous research suggested that in general, high endorsement of heritage culture (enculturation) is associated with more conservative sexual values, narrower repertoire of sexual behaviors, less sexual satisfaction, and less frequency in sexual activities; whereas, high endorsement of U.S. mainstream culture (acculturation) is related with more open attitudes towards sex, increased pleasure and arousal from 
sexual activities, less sexual guilt, and more sexual communication (Brotto et al., 2005; Morton \& Gorzalka, 2013; Woo \& Brotto, 2008; Woo, Brotto, \& Gorzalka, 2011), which potentially leads to higher relationship and sexual satisfaction.

One important component of culture is language. Many bicultural individuals in the US are exposed to both English and their heritage language in various degrees. The number of people in the U.S. who speak an Asian language in addition to English has been steadily rising since 2010 and reached nearly 10 million in 2014 (U.S. Census Bureau, 2014). Previous research suggested that the use of heritage and English language might have an effect on bilingual individuals' values, self-perception, cognitive style, and emotional expression by eliciting heritage and mainstream cultural mindsets respectively (Benet-Martínez, Leu, Lee, \& Morris, 2002; Boucher \& O’Dowd, 2011; Chen \& Bond, 2010; Chen, Lam, Buchtel, \& Bond, 2014; C. Y. Cheng, Lee, \& Benez- Martínez, 2006; Hong, Morris, Chiu, \& Benet-Martínez, 2000; Lee, Oyserman, \& Bond, 2010; Marian \& Neisser, 2000; Matsumoto, Anguas-Wong, \& Martinex, 2008; Oyserman \& Lee, 2008; Trafimow, Silverman, Fan, \& Law, 1997; Verkuyten \& Pouliasi, 2006). Because language triggers a different cultural mindset that likely influences sexual attitudes and values, the communication skills and sexual knowledge learned in English in a mainstream American setting may not be readily transferrable for Chinese bilinguals in their interaction with partners. Studies on bilinguals' language preference with their partners in intimate and sexual relationships were surprisingly scarce, and it is unclear how language and cultural mindset may be associated with bilinguals' sexual communication and intimate interaction. 
In order to better understand the association of acculturation and language preference with attitudes and behaviors in sexual and romantic relationships, and potentially inform culturally relevant sexual education, the current study evaluated acculturation processes and language use (i.e., native language vs. English), as they relate to the romantic and sexual experiences of bilingual Chinese young adults in the U.S. Specific hypotheses were: (a) greater endorsement of mainstream American culture was expected to be associated with greater sexual assertiveness and lower endorsement of traditional gender roles in intimate relationships. In addition, because language is assumed to serve as a prime for a cultural mindset, (b) it was expected that Chinese heritage bilinguals would use English and Chinese to accomplish different goals or address different topics in their relationships. 


\section{CHAPTER II}

\section{REVIEW OF LITERATURE}

The following literature review will discuss the origins and developments of sexuality and gender roles throughout Chinese and American history, the effect of acculturation on Chinese American young adults' attitudes and experiences in intimate relationships, and the use of cultural mindset triggered by heritage and English language in Chinese individuals.

\section{Cultural Context}

To better understand the influence of acculturation and the existing differences between Chinese and White populations, it is essential to take a closer look at the historical contexts of Chinese and American sexual values. Ancient Chinese philosophies held a positive and open attitude toward sex (Ruan, 1991). I-Cheng, the earliest overarching philosophy work that influenced all aspects of Chinese society development including politics, medicine, religion, philosophies, and sexual and gender values, introduced the concept of Yin and Yang (Ruan, 1991). Yin-Yang is a dichotomous concept that can be used to depict any pair of concepts that are considered to be opposites. In the aspect of gender, Yin stands for women, female, and femininity, whereas Yang stands for men, male, and masculinity (Wang, 2016). Canonic texts from both Confucianism and Daoism invoked the Yin-Yang to conceptualize sexual relationships and gender roles. Original Confucian work regarded sexual impulses as natural and important, and viewed sex as necessary means to fulfill marital and reproductive 
obligations (Ruan, 1991). Philosophical Daoism emphasized the importance of harmonious sexual life to physical health and longevity, leading to the development of special sexual techniques in later Dynasties. Although the Yin-Yang concept emphasized the complementary nature of Yin and Yang rather than subordination, because of the patriarchal society structure, pre-Qin Confucianists and Daoists focused on men and took little interests in the issues of women (Woo, 2016).

Over the past two thousand years, a number of major philosophies and religions transitions contributed to the gradual endorsement of more suppressive female roles (Woo, 2016). In Han Dynasty (202 BC - 220 AD), the first Chinese imperial dynasty that endorsed Confucianism, Banzhao employed the concept of Yin-Yang in her Confucian work Nvjie to urge parallel education for women and men because the Confucian education at the time was only developed for men. She and her followers advocated for mutual respect and love within a couple and suggested that excessive intimacy led to lust and trouble for men. Early Confucianism primarily appealed to the ruling class and was not concerned with ordinary people. Although the women's primary responsibility was the inner realm (home and family), in order to obtain power and status, elite men were advised to listen to the womenfolk (their mothers, wives, and even daughters) who were viewed as valuable consultants rather than subordinate to men. Nevertheless, Banzhao and other early Confucianists' work implied women's inferiority to men, because Yin is often associated with negative qualities and Yang with positive ones.

Under the influence of the patrilocal structure of ancient China, women assumed domestic roles and had various obligations to their sons, brothers, and fathers in early 
Confucianism (Goldin, 2016). Although the association between women and domestic roles originated from Confucianism, multiple philosophical, religious, and political forces contributed to the increasing restriction of freedom for women (Woo, 2016). The rise and popularity of Buddhism profoundly impacted the society's understanding of women since the late Han Dynasty because it was accessible to both elite and ordinary women during the post Han wartime $(220$ - 581 AD). Buddhism associated women with darkness, softness, and weakness, and suggested that women were born with major flaws, sins, and impurity because of their sins from previous lives, which reinforced the notion that the female body was inferior to the male body. Under the influence of Buddhism, the philosophy of Daoism branched out into religion and started religious Daoism that adopted several aspects from Buddhism including the misogynist notion of feminine impurity. In Tang Dynasty (618-907 AD), Buddhism was particularly influential, leading to a wide spread fear of feminine seduction that was considered to interfere with enlightenment and the perception of women as pollutants. Moreover, Buddhism attempted to "buddhisize" Confucian values such as filial piety through stories like Maha-Maudgalyana, which dramatized the evil nature of women. The narratives from religious Daoism also reflected the corrupting nature of sexual indulgence and the notion of physical impurity, reinforcing the idea of feminine immorality. Such religious influences extended to the realm of medicine and contributed to the medical assertion that women were controlled by emotions and desires.

Under the Song Dynasty (960-1127 AD), Confucianism regained dominance in the ruling class, whereas Buddhism and Daoism continued to appeal to the ordinary 
people (Woo, 2016). Distinct from the misogynistic notions in Buddhism and Daoism to preserve personal salvation, Confucianism was primarily concerned with feminine influence in politics that were perceived as malfeasance resulting in cultural and political ruin. However, the overlapping themes between Neo-Confucian and Buddhist narratives suggested that Neo-Confucianism was likely to have synthesized its antipathy to women and extreme reconceptualization of virtue for women from Buddhism. Neo-Confucianism developed the principle of li that rationality is the foundation for all truth, which justified the subordination and control of emotional and reckless women who lacked good sense. Neo-Confucianism narrowed the qualities of noble women into only two categories. A woman was either "chaste and virtuous" (Woo, 2016, p. 59) such as a faithful wife that does not remarry, or "wicked and pernicious" implying that she causes familial and imperial destruction. Both Buddhism and Confucianism commanded women to sacrifice themselves to serve the family interests and filial piety, either as penance for sins from the previous life in Buddhism or to strive for merits of virtue and faithfulness in Confucianism.

The asceticism and Puritanism that emerged in Tang was increasingly merged with political agenda of social stability and national security (Woo, 2016). The trend peaked in the Ming Dynasty (1368 - 1644 AD) and resulted in the devaluation of sexual pleasure for both men and women and increasing fear of feminine seduction in the mainstream culture. The first official policy regulating individual sexual behaviors started in the Song dynasty and the government exerted increasing control over sexuality for noble and ordinary men and women. By the Ming Dynasty, the government had 
developed systematic repressive institutions and policies, which continued throughout Ming and Qing Dynasties and exert great influence in modern day (Ruan, 1991).

In many Confucianism-based collective cultures, parents maintain authority over young adults' choices for dating and marriage. In traditional Chinese families, parents or guardians usually arrange marriages for the children because marriage is viewed as a union of two families instead of two individuals (H, Kim et al., 2012; Lee \& Mock, 2005). Currently, the majority of young Chinese adults have the freedom to date whoever they prefer, but they still tend to ask parents' permission for marriage (H. Kim et al., 2012). Chinese cultures have also traditionally held strong double standards for women and men's sexuality (Yan, Wu, Ho, \& Pearson, 2011; Youn, 2001). Neither Chinese women nor men believe that women should desire sex as much as men or that sex should be enjoyable and satisfactory for women (Yan et al., 2011). In an Asian study that included Chinese participants, Asian parents were generally more intolerant of their daughters' premarital sexual behaviors than sons'. Daughters are more likely to receive parental talks on sexuality, which often emphasize aversive consequences of premarital sexual behaviors. Sons are less likely to receive such talks, and when they do, parents sometimes encourage sexual exploration in the conversations (J. L. Kim \& Ward, 2007). In addition, it is considered taboo to discuss sexual topics and parents usually use indirect ways to convey sexual values and expectations to their children in China (J. L. Kim \& Ward, 2007; Zhang, Li, \& Shah, 2007). Chinese adolescents often obtain limited knowledge on sexuality from teachers and parents, and thus turn to peers and mass media for more tabooed information (Zhang et al., 2007). 
Because of limited literature available on cross-cultural studies that specifically compare Chinese to White counterparts on romantic and sexual relationship (one result on PsycINFO), studies that compare Asian and White American were accessed for this literature review. Gender differences in sexual values and behaviors are more prominent among Asian than White counterparts. Asian men report more sexual problems and dissatisfaction than White men, and women report more sexual avoidance than White women (Woo \& Brotto, 2008). Both Asian and White American men report more negative attitudes about same-sex relationships than women, whereas women report more negative attitudes towards uncommitted sexual relationships than men (Meston et al., 1998). The conservative value and communication styles towards sex might potentially decrease Eastern Asian immigrant's exposure to sexuality education, lower their tendency to talk about sex related topics, and increase their risky sexual behaviors. Compared to White American counterparts, Eastern Asian immigrants were likely to have later sexual initiation ages (Grunbaum, Lowery, Kann, \& Pateman, 2000), more conservative attitudes towards sex, and engage in less variety of sexual activities (Meston et al., 1996).

Compared to Chinese cultures, American culture holds a more open and egalitarian view on sexuality. However, historically Western societies such as Europe and England still considered sex outside marriage as illegal and immoral, and these behaviors (by women) were punishable by fining, flogging, imprisonment, and even death (Dabhoiwala, 2012). These notions were first challenged between 1660 and 1800, when new ideas emerged in England, such as viewing sex as a private matter, sexual behavior 
as a matter of personal choice rather than moral responsibility, women as having the same self-control over temptations as men, and sex as something that should be celebrated instead of suppressed.

American society inherited its initial conservative sexual norms from England. Social norms in the U.S. on sexuality started to shift in the 1960s from conservative sexual values to increasing acceptance of sexual behaviors outside heterosexual wedlock. Women demonstrated a dramatic increase in premarital sexual behaviors between 1965 and 1985, along with increased endorsement of the notion that premarital sexual behaviors were irrelevant to morality (Robinson et al., 1991). The program of research and development of sex therapy interventions by Masters and Johnson (1976) emphasized a new focus on increasing sexual pleasure and embracing sexual freedom. Today, sex has become increasingly central to mainstream Canadian and U.S. popular culture, due to the proliferation of mass media and the Internet (Garlick, 2011; McNair, 2002). Various media forms, including adverting, TV shows, movies and art, contain more and more sexual elements, which reflects the increasing openness to various sexual activities in general in Canadian and U.S. society.

It is in this complex cultural context that Chinese young adults in the U.S. negotiate romantic and sexual relationships to develop intimacy. Given the potential for conflicting values and variable socialization experiences, it is important to understand the subjective experiences of Chinese young adults as they navigate the developmental task of intimacy. 


\section{Acculturation Among Asian American Young Adults}

Acculturation studies on Chinese bilinguals were surprisingly scarce. PsycINFO yielded four relevant studies when typed in keywords like "acculturation, Chinese, sexuality" and "acculturation, Chinese, romantic relationship". Thus the acculturation section used a broader panethnic label "Asian" to discuss the model and effect of acculturation on sexual and romantic relationship.

\section{Models of Acculturation}

Unidimensional models of acculturation place individuals on a continuum from complete engagement with mainstream values and norms to complete embeddedness in heritage culture (Ryder, Aldsen, \& Paulhus, 2000). Unidimensional models presume a process of assimilation, in which adaptation to the mainstream culture would necessarily decrease the individual's connection to the heritage culture. Common measurements of acculturation use demographic variables to approximate the individual's level of mainstream acculturation, including length of residency in the new culture, generational status, place of birth, or age at immigration. These measurements are based on an underlying assumption that the longer the individual stays in the new environment, the more exposure he/she would receive from the mainstream culture, and thus he/she would be more acculturated to the mainstream norms. Acculturation is also often measured through assessment of the language used at home, based on similar assumptions to demographic variables. An individual's language exposure is a proxy for the level of exposure he/she has with mainstream culture.

Despite the prevalent use of such proxy measurements for acculturation, they fail 
to take into account individual differences and other environmental factors that influence adaptation rate (Ryder et al., 2000). Variables such as length of residence alone cannot fully capture all the facets associated with acculturation, and do not properly account for the developmental process of a bicultural identity (Brotto et al., 2005). For instance, there are alternative explanations to the correlations between "length of residence" and observed cultural difference. Factors such as previous contact with Western culture, residence in an ethically homogenous neighborhood, exposure to heritage culture, and willingness to adopt the new culture are independent of the length of residence, and may be responsible for acculturation differences.

As an alternative to unidimensional models, which put mainstream culture and heritage culture at opposite ends of a continuum, bidimensional models independently assess endorsement of both mainstream and heritage cultures (Brotto et al., 2005; Meston \& Ahrold, 2010; Woo \& Brotto, 2008; Woo et al., 2011). Bidimensional models have two core assumptions. First, individual differences exist in the extent to which culture influences self-identity (Ryder et al., 2000). Culture may significantly affect values and behaviors in some individuals, but have little impact on others who may consider other factors more important such as religion or occupation. Second, individuals are able to have more than one cultural identity with independent level of strengths.

A core tenet of bidimensional models is that identification with mainstream and heritage cultures is independent or orthogonal. Individuals can be highly identified with both, only one, or neither culture. There are four general conceptual categories to describe engagement in mainstream and heritage cultures (a) Assimilation: individuals 
strongly identify with and seek to fit in the mainstream culture and no longer maintain their heritage identity (i.e., high level of mainstream identification and low level of heritage identification); (b) Separation: individuals endorse only heritage culture (i.e., high level of heritage identification and low level of mainstream identification); (c) Integration: individuals maintain both mainstream and heritage cultural identities (i.e., high levels of identification with both mainstream and heritage cultures); (d) Marginalization: individuals adapt neither culture (i.e., low levels of identification with both cultures; Berry, 1997).

Individuals who exist in the space between two cultures must navigate some sort of bicultural adaptation, as they strive to integrate a heritage culture with a new mainstream or host culture. The construct of bicultural identity integration (BII; BenetMartínez \& Haritatos, 2005) addresses experiences as individuals negotiate multiple cultural influences. BII assesses individuals' experience of culture distance (the degree of dissociation vs. fusion between two cultural identities) and culture conflict (the degree of opposition vs. compatibleness of the two cultures). In a sample of first generation Chinese American adults, language related stress, adherence to heritage culture, and isolation from a culturally similar community predicted high levels of cultural distance (i.e., viewing two cultures as dissociated or separated). A history of negative crosscultural interactions (e.g., discrimination) and language related stress predicted high levels of cultural conflict (i.e. perceiving two cultures as oppositional). Individuals with low BII may experience higher acculturation stress and cultural tension (Benet-Martínez et al., 2002). 


\section{Acculturation and Sexual and Romantic Behaviors/Attitudes}

Previous research using unidimensional models found that recent Asian immigrants tend to hold more conservative sexual attitudes than long-term Asian immigrants and European counterparts. Tong (2013) used a sample of Asian American youth from the National Longitudinal Study of Adolescent Health (Add Health) database, and examined the sexual behaviors of adolescents over seven years at both individual and community levels. Acculturation was measured by three indicators: immigration generation, language spoken at home, and language spoken at the community level. Overall, acculturation to U.S. culture was linked to more liberal sexual activities among adolescents. Earlier first-time sexual intercourse was associated with higher immigration generation status, speaking English at home (for women), more permissive parental attitudes towards sex, and living in a lower SES neighborhood. Having more sexual partners was related to speaking English at home (for women), having more English speakers in the neighborhood, having parents that graduated from high school, not going to church, and previous history of cohabitation.

Kao, Lovelang-Cherry, Guthrie, and Caldwell (2011) used Waves 1 to 4 in the Add Health database to explore the relationship between mother-child sexual communication and initial sexual intercourse. They focused on mother's perceived interaction with adolescents on the topics of sexuality and adolescents' perceived sexual expectations from mother. Acculturation was assessed by the language spoken at home and length of residency. Speaking English at home was associated with mothers' increased sense of being comfortable discussing sexual topics with their adolescents and 
being trusted by their adolescents to collaborate on sexual decision-making. Speaking English at home was also related to adolescents' perceptions of their mother's approving attitude towards sex and earlier sexual initiation.

Koo, Stephens, Lindgren, and George (2012) surveyed White and Asian American male undergraduate students' misogynistic beliefs, ethnic identity, and acculturation. Compared to White counterparts, Asian American men reported more rapesupportive beliefs, such as lower perpetrator blame, higher victim blame, lower refusal credibility, and lower rate of defining acquaintance rape incidents as rapes. Misogynistic beliefs, such as hostile, mistrusting, and devaluating notions about women, partially mediated the effect of ethnicity in all rape-supportive beliefs. Ethnicity was associated with perpetrator blame and victim blame above and beyond acculturation.

Brotto et al. (2005) surveyed White Canadian and East Asian women on their sexual function, sexual experience, and sexual arousability, as well as East Asian women's acculturation using both unidimensional and bidimensional measurements. Although no ethnic differences were observed in relationship satisfaction and sexual dysfunction, East Asian women reported significantly lower desire, lower arousal, lower sexual frequency, lower sexual receptivity, lower pleasure with orgasm, and higher anxiety in response to anticipated arousal than White Canadian counterparts. For East Asian women, years in Canada (unidimensional measurement) were positively related to sexual knowledge, liberal sexual attitudes, and sexual experiences. However, the results from bidimensional measurement suggested that enculturation alone was negatively associated with liberal sexual attitude, and only women with low enculturation had 
increased liberal sexual attitudes when their acculturation increased. Asian women who endorsed higher acculturation reported more sexual experiences. Moreover, results from unidimensional measurement indicated no significant relationship between sexual arousal and acculturation, whereas the results from bidimensional measurements suggested that high endorsement of acculturation predicted increased mental arousal, genital arousal, and pleasure from genital touch. Unidimensional results suggested a negative association between acculturation and anxiety from sexual arousal, but bidimensional results found only acculturation was negatively associated with anxiety relevant with sexual arousal.

Woo and Brotto (2008) conducted a survey with Asian and White Canadian undergraduate students to examine the association between acculturation and sexual complaints. Asian ethnicity was linked with more sexual complaints such as higher sexual avoidance, more sexual dissatisfaction, and increased non-sexuality relative to Whites. Across Asian and White ethnicities, being male was associated with more sexual problems and higher sexual dissatisfaction, whereas being female was linked with increased sexual avoidance. Within the Asian sample, lower endorsement of mainstream culture was associated with increased sexual problems, more sexual non-communication, higher sexual avoidance, and more nonsexuality. Higher endorsement of ethnic culture was predictive of higher sexual avoidance. The results suggested that a strong affiliation with the mainstream culture and a weak connection with the ethnic culture predict more positive sexual attitudes.

Woo et al. (2011) surveyed 242 East Asian and White women on their sexual function, sexual conservatism, and sexual guilt, as well as Asian women's acculturation. 
Between-culture comparison suggested no differences in sexual experiences between White and Asian women except for touching with clothing removed, toughing of partner's genitals, and engaging in sexual intercourse. White women reported higher sexual desire, lower sexual conservatism, and lower sex guilt than East Asian women. Sex guilt and sexual conservatism individually mediated the ethnicity difference in sexual desire. For East Asian women, lower endorsement of the mainstream culture was associated with more sex guilt. Sex guilt mediated the effect of mainstream acculturation on sexual desire.

Morton and Gorzalka (2013) recruited White and East Asian Canadian female undergraduate students to study sexual beliefs and thoughts on sexual experiences. Compared to White counterparts, East Asian women reported significantly more traditional sexual beliefs such as sexual conservatism, sexual desire as a sin, age-related beliefs, body image beliefs, denying affection primacy, and motherhood primacy. East Asian women's traditional sexual beliefs were positively associated with ethnic acculturation and negatively linked with mainstream acculturation. Moreover, traditional sexual beliefs, especially sexual conservatism, were significantly connected to sexual functioning among East Asian women. However, the study suggested that the traditional sexual beliefs Asian women endorsed were dysfunctional, which assumed the western perspective of liberal sexual beliefs as functional. The assumption is not founded and the traditional sexual beliefs are as functional as the more liberal ones.

In summary, these studies indicate that the bidimensional model has great utility in studying Asian sexual behaviors and attitudes because it provides a more 
comprehensive framework for understanding cultural identity change, and opportunities to investigate the interaction effects of both cultures on individuals.

\section{Language Priming and Cultural Mindset}

Cultural mindset was defined as a mental representation involving culturecongruent content, procedures, and goals (Oyserman \& Lee, 2008). Lee et al. (2010) suggested that collective cultural mindset is distinct from that of individualistic cultures on cultural perceptive. For instance, the collective cultural mindset endorses the idea of humility and fitting in (content), uses interpersonal connection and assimilation (procedures) to process social information, and works towards collective wellbeing (goal); whereas the individualist mindset emphasizes being positive about the self and being different (content), contrasting or separating self from others (procedures), and striving for individual success (goal). As part of culturally bound values, sexual attitudes and gender roles are derived from, and thus influenced by the cultural mindset. The collective cultural mindset represents the Confucian and Neo-Confucian doctrine, which in the context of gender role and sexuality, includes the emphasis on harmony and authoritarianism (content) in order to achieve the wellbeing and continuation of the patriarchal family (goal) by restricting sexual activities and women's role as submissive caretakers of the family (procedures). The individualistic cultural mindset embodies the notion of being positive about self (content) to achieve individual independence and freedom (goal) by striving for gender equality (procedures).

Priming refers to the process of using a task that cues concepts, knowledge, and 
goals that would have a carry-over effect on subsequent tasks (Oyserman \& Lee, 2008). Culturally specific primes such as language and cultural icons tend to activate a mental schema that prompts a temporary cultural mindset in which subsequent information is processed. Individualistic and collectivistic cultural cues elicit specific cultural mindsets and influences individual's values, self-concept, relationality, well-being, and cognitive style. In their meta-analysis of various studies on language priming, Oyserman and Lee (2008) summarized the following results. The priming of collectivistic and individualistic cues elicits corresponding cultural values consistently across multiple studies with Asians and European Americans. Cultural priming had a moderate to large effect on how participants engaged with others, but relevant studies were only on Western samples. Primed individualistic culture reduced the importance of social context in self-concept to a larger extent than primes for collectivistic culture promotes it. Cultural priming influenced cognitive style in the moderate to high range. Both cultural frames influenced cognitive style: individualists tended to employ contrasting procedures while collectivists endorsed connecting procedures.

The cognitive shift elicited by cultural cues among bilinguals has also been described with the concept of cultural frame switching (CFS; Hong et al., 2000). A series of studies conducted in Hong Kong showed that Chinese college students in Hong Kong who were exposed to the iconic pictures of Chinese culture and asked to write about them showed more endorsement of external attribution in social situations, whereas those in the American culture condition (i.e., viewing and writing about American icons) had significantly less endorsement of external attribution. Exposure to a cultural icon greatly 
increased the accessibility to the corresponding cultural schema.

Chen and Bond (2010) conducted a series of experimental studies based on the cultural accommodation hypothesis to assess the effects of language (i.e., English vs. Chinese) on participants' ratings of personality characteristics. The cultural accommodation hypothesis suggests priming mindsets evoke bilinguals to change their self-perceptions and behaviors to accommodate the cultural norm of whom they interact with. In the first study, 213 bilingual college students from Hong Kong were randomly assigned to receive study materials in English or Chinese. They were asked to complete a personality inventory rating (a) themselves, (b) a typical native Chinese speaker, and (c) a typical native English speaker. Native Chinese speakers were rated higher on neuroticism and conscientiousness, whereas native English speakers were perceived as more extraverted and open. Completing the measures in Chinese slightly increased perceived neuroticism self-rating. In a second study, 76 bilingual female students from the same university were assigned to interview conditions with either White or Chinese interviewers speaking either English or Chinese (four total conditions). With a White interviewer, bilinguals were perceived by an independent observer as more extraverted, open, and assertive (closer to the prototype of White individuals) in both English and Chinese speaking conditions. With a Chinese interviewer, bilinguals exhibited White prototype in the English speaking condition, but not in Chinese speaking condition. The priming effect of the ethnicity of the interlocutor seemed to be more prominent than that of language.

In another set of studies, Chen et al. (2014) again confirmed the effect of language 
priming both the expressed personality as well as self-perceived traits towards the presumed social norm of corresponding ethnic culture. Hong Kong bilinguals reported higher self-ratings on competence and conscientiousness in English than in Chinese, which is consistent with the norms of self-perception in Western culture and Chinese culture. Speaking English resulted in higher ratings on communicated competence and conscientiousness with both White and Asian interviewers in self-perception as well as other's observation. However, the language priming effect was weakened when the interviewer was White.

Lee et al. (2010) conducted a series of studies among bilingual Hong Kong students on cultural mindset and its effect on self-enhancement, the tendency to rate self high on desirable traits and rate others high on undesirable traits. When the study materials were administered in English, the bilingual participants were more likely to show self-enhancement compared to those in Chinese-language condition. In a second study, the participants were asked to write about a failed or successful previous attempt to resist temptation (moral failure/success) in either Chinese or English. Those who wrote in English also showed self-enhancement, regardless of the moral content of the experience. The language functions as a prime for cultural mindset, which activates or deactivates the tendency to self-enhance in social comparisons.

Moreover, language priming is moderated by bicultural identity integration (BII). Benez-Martínez et al. (2002) conducted three studies on BII's moderating effect on cultural mind shift. In study one, they recruited 65 first generation Chinese American college students that lived in both the U.S. and a Chinese country or region for at least 
five years. BII was measured by a short vignette. The participants with high BII and low BII were randomly assigned into Chinese priming group and American priming group. After the participants were shown iconic pictures of Chinese culture or American culture, they were asked to interpret the reason an animated fish swam away from other fish, which measured participant's internal and external attribution level. The results suggested that individuals with high BII reacted consistently with the primed culture (stronger internal attribution when primed with American culture, strong external attribution when primed with Chinese culture), whereas individuals with low BII behaved in a primingresistant way (stronger external attribution in American prime condition, and vice versa). In study two, the researchers added additional measurements for attribution and expanded the sample to include high school students. The results of study two generally supported the findings in study one. However, close-ended questions for attribution yielded more significant results than the open-end questions in study one. In study three, the researchers used culturally neutral primes instead of Chinese or American culture primes. Results showed that there was no significant difference between low and high BII in attribution style, suggesting BII does not moderate attribution style in non-culturally specific situations.

C. Y. Cheng et al. (2006) further discussed the interactive pattern between BII and assimilation/contrast effect. The assimilation effect is the priming-consistent response that usually takes place when primes are seen as representative of the culture or congruent with individual's self-concept. The contrast effect is the priming-resistant response that usually elicited by primes perceived as non-representative of the culture or 
dissonant with individual's self-concept. Individuals with high BII are more likely to demonstrate assimilation effect when exposed to the positive cultural primes and exhibit contrast effect when exposed to negative cultural primes. Individuals with low BII show the opposite pattern: they respond to positive cultural primes with contrast effect and negative cultural primes with assimilation effect.

In addition, cultural context may also act as a prime that influences language use. Zhang, Morris, Cheng, and Yap (2013) conducted a series of studies among Chinese students fluent in English and studying in the U.S. In study one, the participants were introduced to either a Chinese or White face as conversation partner and then engaged in a simulated conversation in English. The participants' English fluency was hindered by the Chinese face, suggesting that the priming cues from the ethnic culture interfere with the performance of the second language above and beyond the anxiety elicited by outgroup interaction. In study two, the participants were shown icons of either Chinese or American culture instead of faces. The result is similar to that in study one: Chinese icons interfere with participants' abilities to speak English. In study three, the participants were primed with Chinese, American, or culturally neutral icons, and then completed two translation tasks to name a series of objects in English and Chinese respectively. Chinese primes led to more literal translations than the matching control group, suggesting that Chinese icons elicit increased accessibility of Chinese lexical structure that interferes the cognitive process of the second language, English. Study four further tested the intrusion of Chinese lexical structure in English processing in Chinese cultural context. The participants had more literal-translations after Chinese primes than American primes, 
whereas priming had no effect on literal-translation produced in English. Chinese context made Chinese more readily available but the American context did not increase the accessibility of English.

Finally, in a review on language and bicultural identity among bilinguals, Chen (2015) suggested that cultural mindset underlies the language effect and bilingual individuals change the language they use according to the linguistic context. Languages activate cultural mindset that drives individuals to assimilate to the corresponding social norm in their particular context. Because sexual and gender norms are essentially opposite in traditional Chinese and mainstream American value systems, bilingual individuals may behave differently when different cultural mindsets are activated by Chinese and English. Moreover, memories encoded in one cultural context are more likely to be triggered by the culturally corresponding language than others (Marian \& Neisser, 2000). It is possible that receiving sexual education in English may only increase bilinguals' ability to interact effectively with partner in English contexts but not in Chinese ones.

\section{Summary and Research Questions}

Chinese bilingual individuals experience complex cultural situations as they are exposed to two conflicting sets of values from the American mainstream and Chinese cultures. Such acculturation experiences may have significant effects on their attitudes towards sexual and intimate relationships as well as their interactions with their partners. Moreover, different language contexts trigger distinct bilingual individuals' cultural 
mindset and may lead to cognitive and emotional reactions consistent with either the American mainstream or heritage values. It is important to explore and understand how bilinguals engage in heritage and English language while navigating through these topics. Because U.S. and Chinese cultural contexts socialize men and women very differently regarding their roles in sexual and romantic relationships, all associations were examined separately for men and women.

In this study, the following research questions were addressed:

RQ1: What are the sexual/romantic attitudes and experiences of bilingual Chinese/Chinese American young adults in the U.S.?

RQ2: How are cultural identity and acculturation levels related to sexual and romantic attitudes and behaviors?

RQ3: How do Chinese/Chinese American young adults use their heritage language and English in interpersonal communication about sexuality or romance? 


\section{CHAPTER III}

\section{METHOD}

\section{Design}

This study used self-report survey to examine links among acculturation and attitudes and beliefs about intimate and sexual relationship, and to assess language use in sex relevant discussions within romantic relationships.

\section{Participants}

This study recruited a sample of 18 - to 30 year-old young adults whose ethnic heritage was from greater China region (Mainland China, Hong Kong, Macau, or Taiwan). Eligibility requirements included speaking both English and a heritage language and having at least one romantic/sexual relationship experience. The participants were recruited through a Qualtrics participant panel. Eligibility criteria were provided to Qualtrics and their system recruited and compensated participants. Data collection took place on their secure system, and data were delivered to researchers in an anonymous form. A priori power analysis was conducted to determine the sample size for the study using $\mathrm{G}^{*}$ Power. Assuming medium effect size and alpha of .05 , the study required 68 men and 68 women to obtain power of .80 . Because limited number of participants gave meaningful answers on open-ended questions, additional participants were recruited to make the data from open-ended questions interpretable.

A total of 1,474 participants anonymously accessed the survey and 190 of them 
$($ men $=97$, women $=93)$ were eligible for the study. The average age of participants was $24.99(S D=3.97) ; 52.60 \%$ of participants had a heritage from Mainland China, $34.20 \%$ from Hong Kong, $12.60 \%$ from Taiwan, and .50\% from Macau; $25.3 \%$ of the participants were multiracial. Regarding religious affiliation, $48.9 \%$ of participants were Christian, 33.6\% were Atheist or Agnostic, 11.1\% were Buddhist, and 5.9\% affiliated with Islam, Hinduism, Daoism, or other. Time spent in the heritage country ranged from 0 to 374 months $(M=91.16, S D=91.04)$ and time spent in the U.S. ranged from 3 to 374 months $(M=169.29, S D=104.79)$. Participants also reported their current location in the U.S. $58 \%$ of the participants currently lived on the West coast, $27 \%$ on the East coast, and $15 \%$ in the other areas. Participants also reported the geographic region in which they had spent the most time in the U.S. - $25 \%$ of the participants has lived longest on the East coast, $22 \%$ on the West coast, and $53 \%$ in other areas.

The majority of the participants identified as heterosexual $(n=172)$. Six participants were gay/lesbian, eight were bisexual, two selected "other," and one participant preferred not to say. Finally, participants provided information about their romantic relationship history. The length of longest relationship ranged from 0 to 376 months $(M=56.90, S D=52.82)$, and the length of current relationship ranged from 0 to 374 months $(M=53.23, S D=55.91)$.

\section{Procedure}

This study was reviewed and approved by the Utah State University Institutional Review Board. Potential participants were identified from the Qualtrics panel database 
and received a form email notifying them that a survey was available for which they might be eligible. A link from the email sent potential participants to the online survey. The survey started with a screening tool to screen out ineligible participants (i.e., have no heritage from the greater China region, no romantic history, not bilingual, not 18-30 years of age). After the screening page, a letter of information explained the purpose of the study, the structure of the survey, and the terms of the informed consent (see Appendix A). Participants were forwarded to the survey if they met inclusion criteria and agreed to the informed consent.

\section{Measures}

The measures used in this study are described below and are found in Appendix B.

\section{Acculturation}

Acculturation was measured with the Vancouver Index of Acculturation (VIA; Ryder et al., 2000). The VIA is a 20-item self-report instrument that consists of 10 domains with a mainstream item and heritage item for each domain. The domains include participation in cultural traditions, choice of marital partner, enjoyment of entertainment, endorsement of cultural practices, and others. Sample items from the heritage subscale and mainstream subscale include "I often participate in my heritage cultural tradition" and "I would be willing to marry a White American person." Participants reported the degree of agreement with each statement on a Likert-type scale ranging from 1 (strongly disagree) to 9 (strongly agree). Item scores are averaged for each subscale (Heritage 
subscale and Mainstream subscale) to yield subscale scores. Multiple studies have used the VIA to measure acculturation for Asian American samples to predict sexual function, sexual desires, and sexual experiences (Brotto et al., 2005; Woo et al., 2011; Woo \& Brotto, 2008). It was highly internally consistent (Cronbach alphas $=.91-.92)$ in the norm sample of individuals from Chinese, non-Chinese East Asian, and non-Englishspeaking non-East Asian descent (Ryder et al., 2000). Concurrent validity has been demonstrated by significant relationships with percentage of time lived in West, percentage of time educated in West, generational status, anticipation of remaining in West, using English as first language, self-identification as a Westerner, and the mean score of Suinn-Lew Asian Self-Identity Acculturation Scale. For this study, the Cronbach's alpha for heritage and mainstream acculturation subscales was .848 and .829 respectively.

\section{Bicultural Identity Integration}

BII was measured by Bicultural Identity Integration Scale-Version 1 (BIIS-1; as cited in Benet-Martínez et al., 2002). The BIIS-1 is an eight item self-report measure that assesses cultural conflict and cultural distance. Each item is a statement about the respondent's engagement or attitudes towards the mainstream and heritage culture. Participants report their agreement with each statement on the modified scale ranging from 1 (strongly disagree) to 9 (strongly agree). The scores on two subscales (cultural conflict and cultural distance) are calculated by averaging the items within the subscales. Sample items of cultural conflict and cultural distance subscales include "I am simply a Chinese who lives in North America" and "I am conflicted between the American and 
Chinese ways of doing things." The BII was used in a study on language use in bilingual Chinese/Chinese American with acceptable internal consistency (alphaconflict $=.74$, alphadistance $=.69$; Benet-Martínez \& Haritato, 2005). The Cronbach's alpha for the distance and conflict subscales in these data were .521 and .618 , respectively. Evaluation of inter-item correlations and scale statistics indicated that deleting the last item in the conflict scale increased reliability to .858 . Therefore, the conflict scale was re-calculated with items five through seven for all subsequent analyses. No item modifications improved reliability for the distance scale.

\section{Sexual Variables}

Sexual variables were measured by Hurlbert Index of Sexual Assertiveness (HISA; Hurlbert 1991), Double Standard Scale (DSS; Caron, Davis, Halteman, \& Stickle, 1993), Dyadic Sexual Communication Scale (DSC; Catania, 1986), and a sexual experiences scale developed for this study.

The HISA is a 25 item self-report instrument that measures the degree of sexual assertiveness of respondents in a relationship with a partner. A sample item is "I feel uncomfortable talking during sex." Participants rate how often they experience the feelings or situations described in the statements on a scale from 0 (All of the time) to 4 (Never). Items 3, 4, 5, 7, 12, 15, 16, 17, 18, 21, 22, and 23 were reverse scored. The scale was normed with a non-clinical sample of 18- to 31-year-old women. A total scale score is calculated by summing all items. The Cronbach's alpha was .910 in the current sample.

The DSS consists of 10 self-report items that assess respondents' degree of acceptance of traditional sexual double standards. Participants reported their agreement 
for each item on a 5-point Likert scale ( 1 = strongly agree, $5=$ strongly disagree $)$, such that higher scores indicate more egalitarian attitudes or less endorsement of sexual double standards. A sample item is "It is expected that a woman be less sexually experienced than her partner". A total score is obtained by summing all items. It demonstrated acceptable Cronbach's alpha (alpha $=.72)$ in a norm sample of 330 college male and female students (Caron et al., 1993). All items were reverse scored to be consistent with the face value of the scale (high score represents high double standard). Face validity and convergent validity tests showed that scale scores are consistent with expectations on the double standards of men and women's use of condoms. The Cronbach's alpha in the current sample was .919.

The DSC is a 13-item self-report scale that measures respondents' perceptions about discussing sexual topics with a romantic partner on a Likert-type scale ranging from 1(strongly agree) to 6 (strongly disagree). A sample item is "My partner rarely responds when I want to talk about our sex life". DSC demonstrated moderate Cronbach's alpha (.81) and good test-retest reliability (.89) in a pilot sample of 144 college students (Catania, 1998). A single scale score is calculated by summing all items. The Cronbach's alpha in the current sample was .894 .

The sexual experiences scale is a 10-item questionnaire developed for this study to obtain information on participants' perception of couple's sexual activities. The first two items are open-ended questions and the following 10 times were on a 9-point scale to assess sexual experience and sexual passiveness (items 1-6: $1=$ none, $9=a$ lot; items 7 10: $1=m e, 9=$ my partner). A sample of the sexual experience scale is "How much 
sexual experience do you think you have?", and a sample of the sexual passiveness scale is "Who usually initiates sex?" Principal components analysis was conducted separately for the sexual experience items (one factor with an eigenvalue of 3.78, which accounted for $63.00 \%$ of the variance; all factor loadings $>.76$ ) and the sexual passiveness items (one factor with an eigenvalue of 2.65 , which accounted for $66.11 \%$ of the variance; all factor loadings $>.57$ ). The Cronbach's alpha for sexual experience was .880 , and for sexual passiveness was .828.

\section{Language Preferences}

Two items asked participants to rate their overall fluency in English and their heritage language on a scale from $1=$ very limited to $9=$ very fluent. Nineteen survey items measured participants' language use in different situations, with different topics, and to serve different purposes on a 9-point Likert-type scale $(1=$ English only, $9=$ Heritage Language only). Principal components factor analysis of the 19 items assessing language use preferences in multiple contexts yielded one factor with an eigenvalue of 14.09 , which accounted for $74.18 \%$ of the variance among the language use items. Thus, all items were strongly inter-correlated, and participants reported consistency across contexts, conversation partners, and topics in their preferred language of communication. The scores of all items were averaged to calculate a total score. The Cronbach's alpha for the scale was high (alpha $=.98)$.

Open-ended questions ask the participants to write specific examples of language use during their interactions with their sexual/romantic partners. A sample item of the open-ended question is "In your romantic relationships or interactions, for which topics 
do you prefer to use English ideally (assuming your partner speaks the both languages)?" The language use measure was piloted by a small group of five people to obtain feedback and modify items.

\section{Demographic and Relationship History Information}

A 16-item questionnaire obtained information on participants' ethnicity, age, gender, length in America/heritage country, current and past relationship status, length of longest relationship, length of current relationship, ethnicity of current or most recent partner, the heritage culture of the current or most recent partner, sexual orientation, number of romantic relationships, current and past total sexual partners, and the ethnicity of the partners. 


\section{CHAPTER IV}

\section{RESULTS}

\section{Descriptive Statistics}

Table 1 presents means and standard deviations for all cultural and sexual variables, along with the results of independent samples $t$ tests evaluating sex differences on all variables. Men endorsed significantly more mainstream cultural orientation, $t(188)$ $=2.45, p=.015$, as well as more distance, $t(182)=5.65, p<.001$, and conflict, $t(186)=$ $3.21, p=.002$, between cultural identities than women. Women reported significantly higher sexual assertiveness, $t(166)=7.00, p<.001$, lower sexual double standards, $t(187)$ $=8.95, p<.001$, and better sexual communication, $t(188)=7.79, p<.001$, than men.

Women also reported preference for English on average; whereas, average scores for men were in the middle of the scale between English and heritage language, $t(179)=4.81, p<$ .001 .

Table 1

Descriptive Statistics for Cultural and Sexual Variables

\begin{tabular}{|c|c|c|c|c|}
\hline \multirow[b]{2}{*}{ Variables } & \multicolumn{2}{|c|}{ Women } & \multicolumn{2}{|c|}{ Men } \\
\hline & M & $S D$ & M & $S D$ \\
\hline Heritage acculturation & 6.87 & 1.18 & 7.01 & 1.09 \\
\hline Mainstream acculturation & 6.95 & 1.04 & 7.31 & .97 \\
\hline BII Distance & 4.12 & 1.20 & 5.00 & .90 \\
\hline BII Conflict & 5.53 & 2.06 & 6.45 & 1.85 \\
\hline Language preference & 3.59 & 2.39 & 5.19 & 2.39 \\
\hline Assertiveness & 90.23 & 15.48 & 75.52 & 11.27 \\
\hline Double sexual standards & 25.88 & 9.39 & 37.30 & 7.99 \\
\hline Sexual communication & 45.87 & 9.99 & 32.47 & 13.40 \\
\hline
\end{tabular}


Table 2 presents descriptive statistics assessing the romantic and sexual histories of participants. Men reported more partners within their own heritage ethnicity than out

\section{Table 2}

Frequencies for Romantic Relationship Variables

\begin{tabular}{|c|c|c|c|c|}
\hline \multirow[b]{2}{*}{ Relationship variables } & \multicolumn{2}{|c|}{ Women } & \multicolumn{2}{|c|}{ Men } \\
\hline & $n$ & $\%$ & $n$ & $\%$ \\
\hline \multicolumn{5}{|l|}{ Relationship status } \\
\hline Single not dating & 14 & 15.1 & 16 & 16.5 \\
\hline Single and dating & 19 & 20.4 & 15 & 15.5 \\
\hline Dating monogamously & 34 & 36.6 & 7 & 7.2 \\
\hline Cohabiting & 3 & 3.2 & 4 & 4.1 \\
\hline Married & 23 & 24.7 & 55 & 56.7 \\
\hline \multicolumn{5}{|l|}{ Ethnicity of current or last romantic partner } \\
\hline Greater Chinese descent & 52 & 56.5 & 81 & 83.5 \\
\hline Other Eastern Asian descent & 9 & 9.7 & 16 & 16.5 \\
\hline South Asian Descent & 11 & 11.8 & 11 & 11.3 \\
\hline Pacific Islander/Hawaiian Native & 2 & 2.2 & 1 & 1.0 \\
\hline Hispanic/Latino(a) & 10 & 10.8 & 5 & 5.2 \\
\hline European descent/White American & 27 & 29.0 & 30 & 30.9 \\
\hline African descent/Black American & 4 & 4.3 & 2 & 2.1 \\
\hline Native American/Alaskan Native & 5 & 5.4 & 5 & 5.2 \\
\hline West Asian/Middle Eastern & 1 & 1.1 & 3 & 3.1 \\
\hline Other & 0 & 0.0 & 2 & 2.1 \\
\hline Multiracial & 14 & 15.1 & 27 & 27.8 \\
\hline \multicolumn{5}{|l|}{ Number of partners } \\
\hline \multicolumn{5}{|l|}{ Romantic partners } \\
\hline 1 & 19 & 20.4 & 25 & 25.8 \\
\hline 2 & 25 & 26.9 & 20 & 20.6 \\
\hline 6 & 20 & 21.5 & 11 & 11.3 \\
\hline 4 & 12 & 12.9 & 5 & 5.2 \\
\hline $5+$ & 17 & 18.3 & 36 & 37.1 \\
\hline \multicolumn{5}{|l|}{ Sexual partners } \\
\hline 1 & 32 & 34.4 & 31 & 32.0 \\
\hline 2 & 21 & 22.6 & 13 & 13.4 \\
\hline 3 & 10 & 10.8 & 11 & 11.3 \\
\hline 4 & 4 & 4.3 & 7 & 7.2 \\
\hline $5+$ & 26 & 27.9 & 35 & 36.1 \\
\hline
\end{tabular}

Note. The participants were asked to check all that apply in the question of the ethnicity of the romantic partners. 
of their heritage ethnicity, $M=7.34, S D=2.18$, whereas women reported almost equal percentage of partners within and out of their heritage culture, $M=5.69, S D=3.15$; $t(188)=4.27, p<.001$. Among the romantic partners with heritage from the greater Chinese cultures, 34 of women's partners and 34 of men's partners were from Mainland China, 11 female and 43 male partners were from Hong Kong, 7 female and 3 male partners were from Taiwan, and 1 male partner was from Macaw. Men perceived their sexual experience, $M=6.33, S D=1.8$, significantly higher than women, $M=5.26, S D=$ $1.63 ; t(187)=4.28, p<.001$. Women, $M=5.89, S D=1.38$, reported similar levels of passivity in sexual activities as men. $M=6.13, S D=1.83 ; t(188)=1.03, p=.30$.

Table 3 presents bivariate correlations among all study variables for both men and women. Heritage acculturation was positively correlated with mainstream acculturation for both men and women. Sexual double standard was negatively correlated with assertiveness and sexual communication, and assertiveness was positively correlated with sexual communication.

Among women, bicultural identity distance was positively correlated with bicultural identity conflict. Among cultural and sexual variables, sexual assertiveness was positively associated with mainstream orientation, whereas double sexual standard was positively associated with heritage orientation and bicultural identity distance. Sexual communication was negatively associated with bicultural identity conflict. Preference for heritage language was positively associated with heritage orientation, bicultural identity distance, bicultural identity conflict, as well as double sexual standard, and negatively associated with assertiveness and sexual communication. 
Table 3

Bivariate Correlations among Cultural variables and Sexual Variables for Woman and Men

\begin{tabular}{lllcccccc}
\hline Variables & 1 & 2 & 3 & 4 & 5 & 6 & 7 & 8 \\
\hline 1. Heritage acculturation & -- & $.30^{* *}$ & .13 & .17 & $.40^{* *}$ & .09 & $.28^{*}$ & -.14 \\
2. Mainstream acculturation & $.69^{* *}$ & -- & -.06 & .07 & -.03 & $.32^{* *}$ & .04 & -.17 \\
3. BII-distance & .05 & -.19 & -- & $.25^{*}$ & $.40^{* *}$ & -.18 & $.32^{* *}$ & -.11 \\
4. BII-conflict & $.57^{* *}$ & $.33^{* *}$ & .04 & -- & $.34^{*}$ & -.16 & $.22^{*}$ & $-.30^{* *}$ \\
5. Language preference & $.36^{* *}$ & .11 & $.34^{* *}$ & $.58^{* *}$ & -- & $-.35^{* *}$ & $.49^{* *}$ & $-.49^{* *}$ \\
6. Assertiveness & .03 & .16 & -.18 & $-.30^{* *}$ & $-.44^{* *}$ & -- & $-.52^{* *}$ & $.30^{* *}$ \\
7. Double sexual standard & $.48^{* *}$ & $.44^{* *}$ & -.13 & $.56^{* *}$ & $.51^{* *}$ & $-.46^{* *}$ & -- & $-.56^{* *}$ \\
8. Sexual communication & $-.47^{* *}$ & $-.51^{* *}$ & .09 & $-.55^{* *}$ & $-.47^{* *}$ & $.39^{* *}$ & $-.81^{* *}$ & -- \\
\hline
\end{tabular}

Note. correlations for men below the diagonal, correlations for women above diagonal. $* p<.05$.

$* * p<.01$.

Among men, bicultural identity conflict was positively correlated with both heritage and mainstream orientation. Among cultural and sexual variables, both heritage and mainstream orientation were positively associated with double sexual standard and negatively associated with sexual communication. Bicultural identity conflict was positively associated with double sexual standard and negatively associated with assertiveness and sexual communication. Preference for heritage language was positively associated with heritage orientation, bicultural identity distance, bicultural identity conflict, as well as double sexual standard, and negatively associated with assertiveness and sexual communication.

Tables 4- 6 present the results of multiple regressions conducted to examine effects of acculturation, language preference, and covariates on sexual variables. After controlling for covariates (i.e., time in U.S. and ethnicity of partners), mainstream 


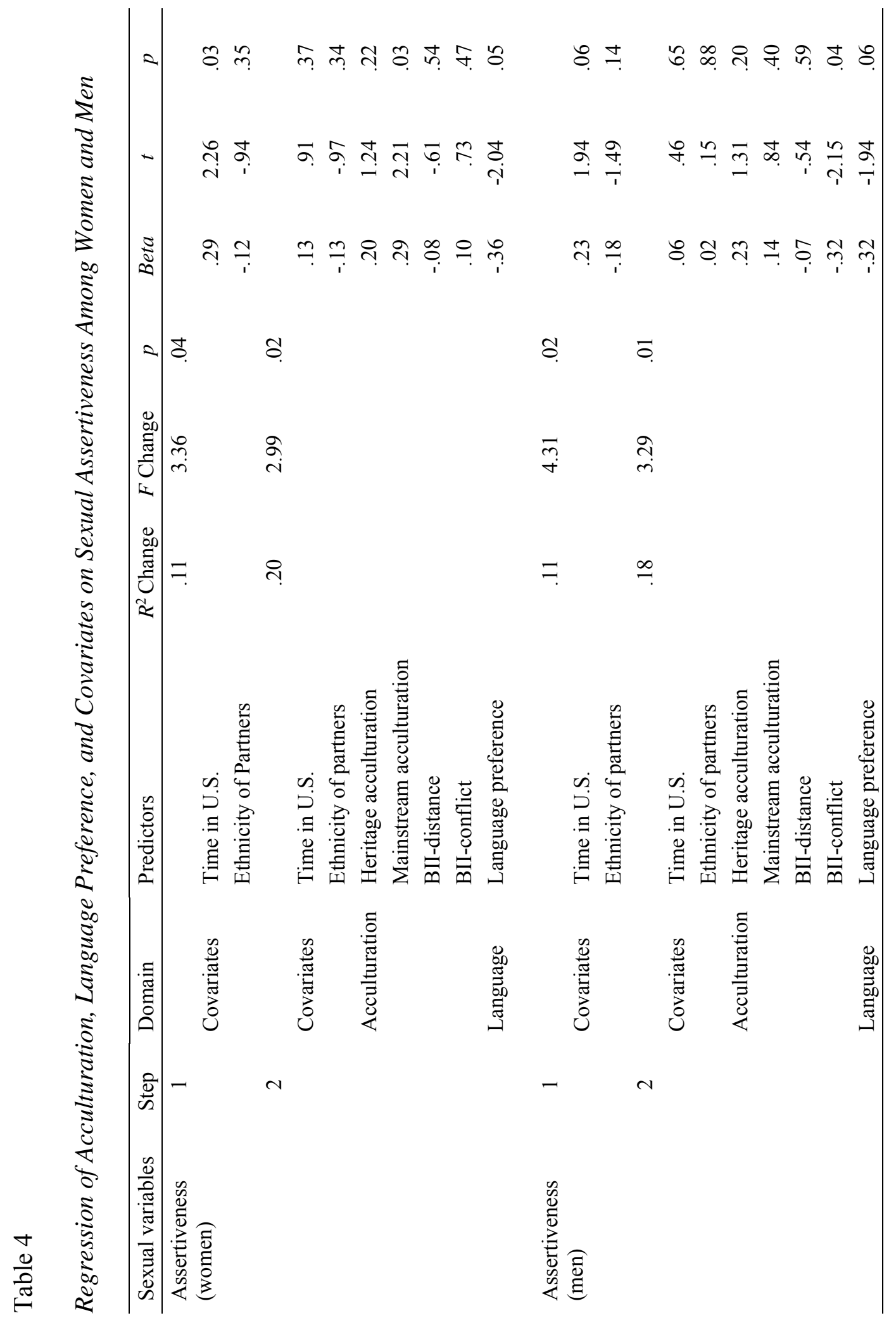




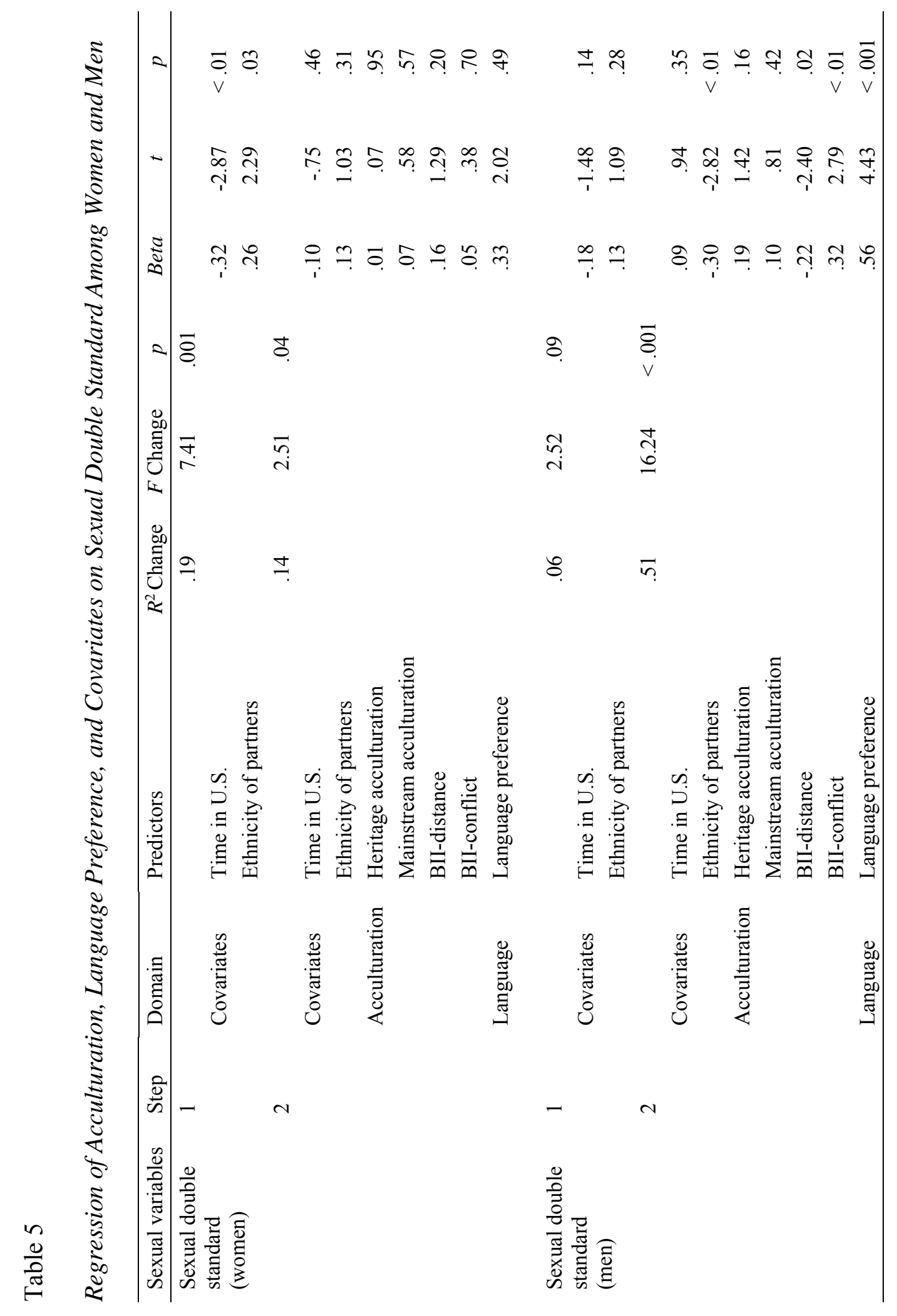




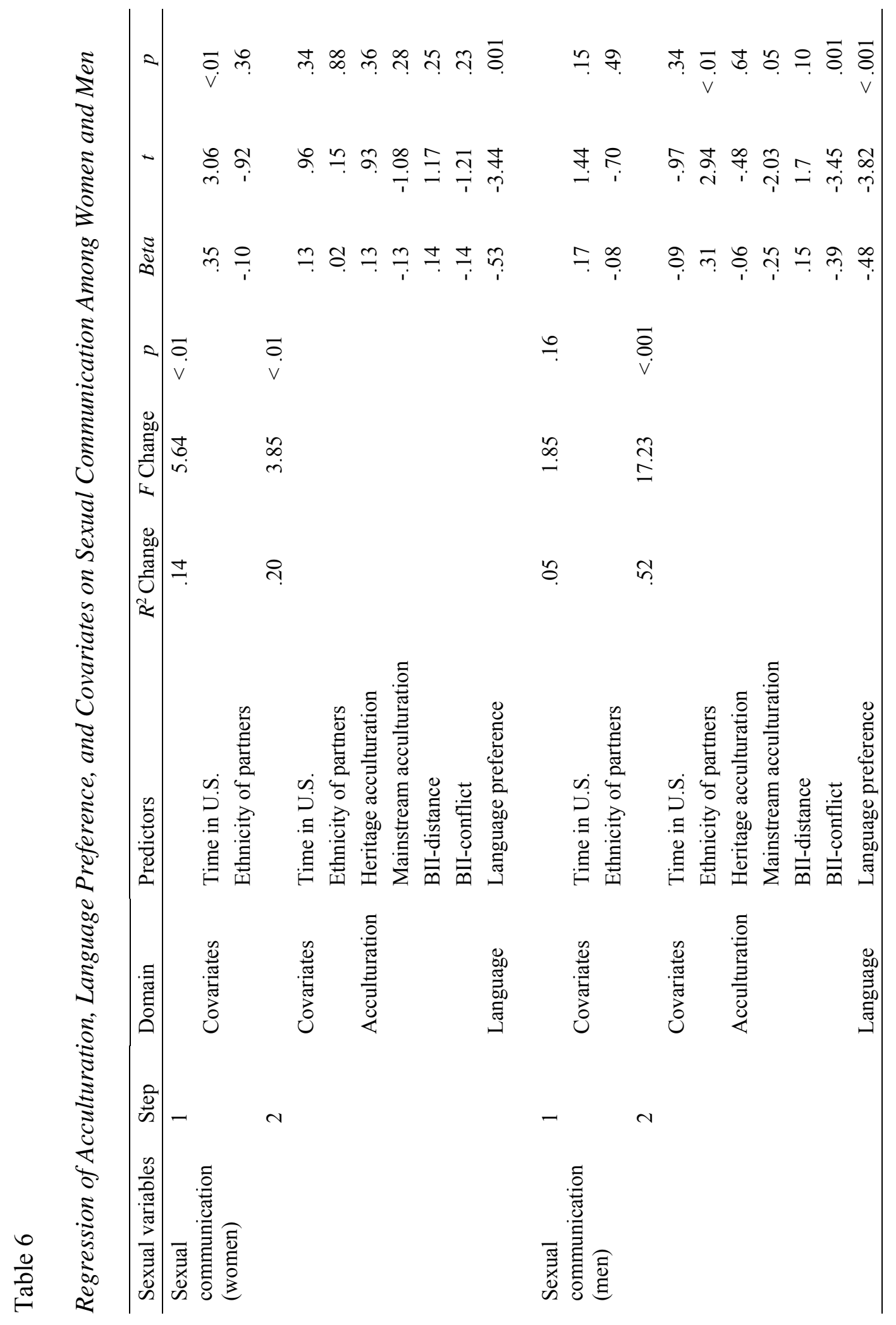


acculturation and language preference were significantly associated with sexual assertiveness in women (Table 4). After controlling for covariates, heritage acculturation, mainstream acculturation and bicultural identity conflict were significantly associated with sexual assertiveness in men (Table 4). Although the $R^{2}$ change was significant in model 2, no variables were significantly associated with double standard for women (Table 5). Ethnicity of partners, bicultural identity distance and conflict, and language preference were significantly associated with sexual double standard in men (Table 5). After controlling for covariates and acculturation variables, language preference was significantly associated with sexual communication in women (Table 6). Ethnicity of partner, mainstream acculturation, bicultural identity conflict, and language preference were significantly associated with sexual communication in men (Table 6).

\section{Review of Open Ended Descriptions of Language Use}

The open ended responses about decisions to use Chinese or English in different relational and task settings were reviewed to determine patterns of language use. The student researcher reviewed every response, categorizing similar responses to create preliminary themes of responses. Preliminary themes were discussed with the major professor, and themes were refined and clarified. Upon agreement of primary categories of response, the student researcher returned to the data and assigned codes to each response. Of the 190 total participants, valid responses for the open ended items ranged from 71 to 86 . Many participants left the open ended items blank, while some left nonsense responses (e.g., random letters or nonsense words). The participants that 
answered the open-ended questions were slightly younger than the whole sample $(M=$ 24.32, $S D=3.96$ ), and the majority of them had heritage from the greater Chinese region $(84.80 \%)$. Compared to the whole sample, they had lower percentage of partners with heritage from the greater Chinese region (38\%), and increased percentage of partners with European descent (33.7\%). Numbers of romantic and sexual partners in the respondents to the open ended items were similar to the whole sample, except that men had higher percentage on 1 sexual partner than that in the whole sample. Table 7 summarizes the themes observed in the open-ended responses.

Around half of the respondents reported using mainly English with their romantic partner regardless of the topics, either because they were more fluent in English or because their only spoke English. It is consistent with the result of factor analysis that language proficiency is the best predictor for language preferences across all topics and English appeared to be the dominant language for the majority of the sample.

Among people who tend to use Chinese to express positive emotions, they reported that Chinese is more expressive, intimate, and more explicit. However, the same reasons were listed by participants who preferred English to express positive emotions, suggesting again that language proficiency drives decisions about language use. Some participants reported that they tended to use Chinese when it was culturally relevant such as talking about Chinese-related topics and "words in Chinese that have no English equivalent" (Female, age 27). One participant also mentioned that the tone expressed by the two languages was different, "Chinese [has a] more aggressive tone [than English]" (Male, age 19). 
Table 7

\section{Qualitative Results of Language Preferences Open-Ended Questions}

\begin{tabular}{|c|c|c|}
\hline Language difference in... & $n$ & $\%$ \\
\hline Expressing positive emotions (valid) & 85 & \\
\hline Partner only speaks English/participant is more fluent in English & 38 & 44.7 \\
\hline English is more expressive/intimate/explicit & 11 & 12.9 \\
\hline Chinese is more expressive/intimate/explicit & 5 & 5.8 \\
\hline Context dependent/cultural difference & 9 & 10.6 \\
\hline Other difference (tone, expression, etc.) & 5 & 5.8 \\
\hline No/little difference & 11 & 12.9 \\
\hline Expressing negative emotions (valid) & 81 & \\
\hline Partner only speaks English/participant is more fluent in English & 40 & 49.4 \\
\hline English has clearer labels for emotion/is issue focused & 10 & 12.3 \\
\hline Chinese expresses stronger emotion/is emotion focused & 15 & 18.5 \\
\hline Context dependent/cultural difference & 3 & 3.7 \\
\hline Other difference (tone, emotional distance, etc.) & 12 & 14.8 \\
\hline No/little difference & 7 & 8.6 \\
\hline Making decisions (valid) & 79 & \\
\hline Partner only speaks English/participant is more fluent in English & 40 & 50.6 \\
\hline English is more compromising/effective communication & 10 & 12.7 \\
\hline Chinese is more compromising/effective communication & 3 & 3.8 \\
\hline Context dependent/cultural difference & 7 & 8.9 \\
\hline Other difference (tone, expression, etc.) & 8 & 10.1 \\
\hline No/little difference & 11 & 13.9 \\
\hline Sexual topics (valid) & 75 & \\
\hline Partner only speaks English/participant is more fluent in English & 40 & 53.3 \\
\hline English is more comfortable/concise/clam & 8 & 10.7 \\
\hline Chinese is more implicit/authoritarian/aggressive & 6 & 8.0 \\
\hline There is no language for sex in Chinese & 8 & 10.7 \\
\hline Other difference (tone, cultural difference, etc.) & 10 & 13.3 \\
\hline No/little difference & 9 & 12.0 \\
\hline English Topics (valid) & 86 & \\
\hline Mostly/all English/daily communication & 58 & 67.4 \\
\hline Sex/relationship & 7 & 8.1 \\
\hline Complex topics/school/work/finance & 8 & 9.3 \\
\hline Other (context dependent, in public, cultural topics, etc.) & 13 & 15.1 \\
\hline Chinese Topics (valid) & 71 & \\
\hline Mostly/all Chinese/daily communication & 9 & 12.7 \\
\hline Sex/relationship/emotion related & 12 & 16.9 \\
\hline Context dependent (family related, private conversation, etc.) & 28 & 39.4 \\
\hline Other (simple phrases, making plans, etc.) & 10 & 14.1 \\
\hline All English (N/A) & 27 & 38.0 \\
\hline
\end{tabular}

Note. Codes do not add up to $100 \%$ because some responses have multiple codes. 
When expressing negative emotions, seven participants reported that English had more concise labels for emotions because English "can explain more of the nuances" (Female, age 24), and is "emotional wise" (Male, age 28). Three participants reported that English is more issue focused and often used when "trying to work out an issue with my partner" (Female, age 24). One participant explained, "[using] English is more willing to talk about it [the problem] and [using] Chinese is kind of a blame game what went wrong" (Male, age 29). On the other hand, thirteen participants reported that Chinese tends to convey stronger emotions and is more emotion focused because "Chinese words are stronger" (Female, age 25) and "more negativity with Chinese" (Female, age 25). The kind of negative emotion expressed matters too. One participant suggested, "Chinese [is] to show I'm much more angry" (Female, age 29). Another participant agreed, “Angry [often expressed] in Chinese, sad in English" (Female, age 25).

However, these themes are not unanimously agreed. Three participants suggested that English conveys stronger emotion and Chinese is kinder or more distant from emotion. Two participants explained that it is because they or their partner are much more fluent in English, "He cannot speak Chinese, and words hurt more in English" (Female, age 26), and "English is more stern and commanding because I have better control over it" (Female, age 27)

On decision-making discussions, seven participants reported that English is more effective and concise for communication than Chinese because English "is better for convincing" (Female, age 27) and "more specific" (Male, age 18). One participant explained, "I cannot fully describe and explain my reasoning [in Chinese]" (Female, age 
18) and "[discussion is] much more blunt in Chinese" (Male, age 20). Moreover, the seriousness and the urgency of the matter affect which language is used. Some participant suggested that "English is more assertive while Chinese is for less urgent decision" (Female, age 25) and 'if it's a serious topic, we use English; if it's not as serious, we use Chinese" (Female, age 22). Two participants reported that English is more compromising than Chinese. However, some participants suggested that Chinese is more effective for communication because they "talk quicker in Chinese and understand quicker too" (Male, age 25), and another two stated that Chinese is more indirect and "more compromising" (Female, age 25). The discrepancy may be explained by participants' proficiency in the two languages. For participants who were more fluent in English, English may have been more effective and compromising, and vice versa.

In addition, seven participants reported that they used Chinese when they were in culturally dependent contexts such as giving Chinese examples or Chinese phrase/slang that has "no good English-language equivalents" (Female, age 24). One participant also suggested that "the person makes the decision" (Male, age 26) will affect the language used: English is used when the couple makes the decision together, whereas Chinese is used when the participant is the primary decision maker.

On sexual topics, seven participants reported that they used English because it was "more comfortable" (Female, age 18), "more vocal and expressive" (Male, 19) or more concise than Chinese. One participant explained, "[Chinese does] not give a clear statement" that "will confuse my partner" (Female, age 19). Eight participants reported that there is no vocabulary for sex in Chinese or it is "more embarrassing" (Female, age 
30) and awkward to talk about sex in Chinese. One participant stated, "[I] don't know how to say anything sexually related in Chinese" (Female, age 25) Another participant explained, "It's harder to talk about sexual activities in Chinese because Chinese people view talking about sex as taboo" (Female, age 18). Language also appears to contribute to the tone of the communication. Four participants reported that Chinese appears more "authoritative" (Male, age 26), and "aggressive and loud" (Female, age 29), whereas English is more "submissive" (Male, age 26) and "calmer" (Female, age 29).

Over half the sample reported using English in almost all topics. In addition to that, seven participants reported using English in daily communications including "activities, family, work" (Female, age 30), and "personal life" (Male, age 24). Another seven participants reported using English in sexual and romantic relationships such as "romantic talking" (Male, age 24) and "in the sex" (Male, age 30). Six participants reported using English for financial topics, and three for complex topics.

Nine participants reported using Chinese in almost all topics or for daily communication. Five participants reported using Chinese in sexual and romantic relationships, and seven reported using Chinese to express emotions. Nineteen participants reported using Chinese in culturally dependent contexts such as talking about "Chinese culture or food" (Male, age 22), "shared experience or background in China" (Female, 2 age 4), family topics involving parents or relatives from China, "political issues related to Chinese government or society" (Female, age 22), "jokes or puns that rely on the Chinese language" (Female, age 19), or when "Chinese-speaking relatives are around." (Female, age 20). Interestingly, seven participants reported that they used 
Chinese with their partner so that they could have a private conversation in public without other people overhearing it, especially for "topics that may not be appropriate in public" (Female, age 23). 


\section{CHAPTER V}

\section{DISCUSSION}

The study aimed to understand Chinese bilingual individuals' acculturation and language preference with partners in romantic relationships, to highlight how their acculturation experience linked to sexual attitudes and interactions with romantic partners. In addition, we explored how bilingual young adults use heritage and English language in various relational contexts. Chinese and American cultures on sexuality and gender roles were mostly in contrast (Brotto et al., 2005; Dabhoiwala, 2012; Garlick, 2011; H. Kim et al., 2012; McNair, 2002; Robinson et al., 1991), thus navigating through the two cultures to develop sexual beliefs and a style of romantic interactions appears to be a unique challenge for Chinese young adults. In addition, previous cognitive studies suggested that linguistic contexts activate cultural mindset, which impacts individual's cognitive and emotional responses (Boucher \& O’Dowd, 2011; Chen et al., 2014; Hong et al., 2000; Oyserman \& Lee, 2008) and potentially influences bilingual individuals' interactions with their romantic/sexual partners. The current study builds upon previous literature by examining the associations among acculturation, bicultural identity integration, and sexual/romantic attitudes, as well as the language preference of bilingual individuals in these topics.

Our evidence supported the hypothesis that high endorsement of Chinese values and low BII was associated with more conservative attitudes about sexuality and gender roles in general, whereas high endorsement of American values and high BII was associated with more liberal attitudes. Men and women also presented different patterns 
of such associations. After controlling for covariates and acculturation variables, language preference appeared to be consistently associated with sexual attitudes in women, whereas BII and language preference appeared to be consistently associated with sexual attitudes for men. Contrary to the hypothesis that choices about language use may have been associated with various contexts and topics, language proficiency appeared to be the most important driving factor for language preference across various contexts and topics. Bilinguals may benefit more from sex education conducted in the language they have higher proficiency on.

\section{Description of Language, Cultural, and Sexual Variables}

Principal components factor analysis of the language preference scale suggested that there is only one global scale for all items assessing language preference across tasks and relationship contexts. Thus, it appears that language proficiency is the predominant predictor of language preference regardless of the contexts or the topics. This finding is inconsistent with previous research on cultural mindsets and language use among bilinguals. According to previous studies, cultural cues in social contexts and environment would prime bilingual individual's cultural mindset, which leads to distinctive response patterns in ways of thinking, self-concept, personality, and emotion expression (Benez-Martínez et al., 2002; Boucher \& O’Dowd, 2011; Chen \& Bond, 2010; Chen et al., 2014; Lee et al., 2010; Oyserman \& Lee, 2008; Trafimow et al.,1997). However, the discrepancy in findings may be due the fact that most research on cultural mindset has used experimental designs that were able to detect nuances that participants 
were not consciously aware of, whereas the current study used a survey method which may not be able to capture such nuances if the participants did not notice them. In addition, the women in the sample had a stronger preference for English than Chinese, which may suggest that they were less proficient in Chinese than in English. The difference in language proficiency may interfere with the effect of cultural mindset.

Descriptive $t$ tests on acculturation and language showed distinct gender differences. Men reported significantly more mainstream cultural orientation, more BII distance, more BII conflict, and lower preference for English than women, suggesting that men were more oriented toward the mainstream culture, and their integration of heritage and mainstream cultural identities was lower than women. C. Y. Cheng et al. (2006) found that low BII predicts contrasting effect with positive cultural primes and assimilating effect with negative cultural primes, which results in the individuals living in a state of "the worst two parts of the worlds." Combined, findings may suggest that bilingual men in general were more susceptible to prolonged cultural stress because the low BII lead them to assimilate to the negative cultural values and contrast the positive ones. Interestingly, although men endorsed more mainstream acculturation, their preference for English was lower than women, which indicates that acculturation may not necessarily be associated with language preference.

Descriptive $t$ tests on sexual and intimacy variables also demonstrated a gender difference. Women reported significantly higher sexual assertiveness, lower sexual double standards, and better sexual communication than men. The gender discrepancy on intimate variables appeared to be partially consistent with previous research. Woo and 
Brotto (2008) found that men reported more sexual problems and higher sexual dissatisfaction across ethnicities, but they also suggested that women reported more sexual avoidance, which was not the case in the current study. Women in this sample appeared to be more communicative and assertive on sex, and held lower traditional double standards than men in general. Women in the sample had more non-Chinese partners and had a preference for English, which means that they were more likely to use English with their partner. It is possible that they have more access to sex education in general and can better transfer the communication and assertive skills learned in sex education to real life scenarios.

\section{Relationships Between Cultural and Sexual Variables}

The correlations among cultural variables are consistent with previous descriptive findings. For men, BII conflict was positively associated with both heritage and mainstream orientations, suggesting that men's integration of two identities decreases as endorsement of the two cultures increases. On the other hand, BII was not associated with heritage and mainstream acculturation among women, suggesting women's BII is not relevant to acculturation level.

The correlations and regression analyses also demonstrated different patterns of associations between cultural and sexual variables. For men, BII conflict was positively associated with double sexual standard, and negatively associated with sexual communication and assertiveness. However, contrary to the hypothesis, both heritage and mainstream acculturation were positively associated with double sexual standard and 
negatively associated with sexual communication at the bivariate level in men. The effect of acculturation was negated in the regression analysis, which suggested that this discrepancy may be explained by strong correlation of BII conflict to mainstream and heritage acculturation. After controlling for covariates, language, and heritage/ mainstream acculturation, BII-conflict was significantly associated with double sexual standards and sexual communication. It appears that the conflict between heritage and mainstream cultural identities is closely related to men's sexual attitudes and behaviors: the more conflict between the two identities, the more conservative sexual attitudes and behaviors men endorse. Helping men to reconcile the conflict between two cultural identities as such decreasing their rigid "either or" thinking with cultural identities and increasing their flexibility in cultural values may contribute to the effectiveness of sexual education.

For women, mainstream acculturation was positively associated with sexual assertiveness, and heritage acculturation was positively associated with double sexual standard, as hypothesized. BII conflict was negatively associated with sexual communication, and BII distance was positively associated with double sexual standard. Similar to men, low integration of heritage and mainstream cultural identities in women is also associated with conservative sexual beliefs and behaviors. However, in the regressions on double sexual standards and sexual communication for women, the associations disappeared after controlling for covariates, language, and other acculturation variables. It appears that acculturation was not associated with sexual attitudes and behaviors when language and covariates were accounted. 
For both men and women, language preference was significantly associated in bivariate correlations with all sexual and acculturation variables except for mainstream acculturation. However, when controlling for covariates and acculturation variables in regressions, language preference showed different patterns for men and women. As the primary component of communication, preference for English was significantly associated with sexual communication in both men and women. But language preference was significantly associated with sexual double standard in men, and with sexual assertiveness in women. The reason for the distinct gender pattern is unclear. It is possible that women are more motivated to focus on practical skills such as sexual assertiveness because they are often expected take the responsibility to "protect themselves", whereas men are more privileged in this regard and thus focus more on sexual attitudes. Nevertheless, it is clear that language is a significant factor associated with sexual behaviors and attitudes, possibly because that there is more education related to gender equality available in English than in Chinese, which provides more opportunities for exposure for both women and men with high proficiency in English. In addition, one of the covariates, ethnicity of partners, stands out in the regression analysis for men's sexual double standard and sexual communication. It remains significant even after the acculturation and language factors are accounted. Having a Chinese-speaking partner is closely related to high sexual double standard and low sexual communication in men regardless of their time in U.S., acculturation level, and language proficiency. This information has important implications for sex educators because demographic data on partner ethnicity is much easier to collect than one's sexual 
attitudes and communication skills.

\section{Open-Ended Questions}

For all open-ended questions, more than half of the participants answered that they only speak or mostly speak English with their partner. Language proficiency and partners' ethnicity appear to be the primary reason for language choice regardless of the content or the topic, which is consistent with the quantitative results. However, the data from the rest of participants who speak both languages relatively well or have bilingual partners yield some interesting themes.

For positive emotions and decision-making, both languages were reported to be expressive and effective from different people. Thus, it appears that the language itself does not have inherent positive or negative characteristics when used for expressing positive emotions and making decisions. It is likely that people find whichever language more efficient when they have higher proficiency in it. But the same rule does not apply to negative emotion and sexual topics. There appeared to be greater consensus that English has clearer labels for emotion and is more issue focused, whereas Chinese expresses stronger emotion and is more emotion-focused when used to express negative emotion. Participants also seem to agree that English is more comfortable and calm for sexual topics whereas Chinese is more implicit and aggressive. The distinction may be a result of different cultural context. For instance, sexual topics are long-standing taboos in the Chinese culture (H. Cheng, 1997; J. L. Kim \& Ward, 2007), thus there is a limited vocabulary to discuss sex, and the existing sexual phrases also tend to carry a significant 
amount of negative emotions such as shame and embarrassment. It is also culturally valued to indirectly convey one's demand or disagreement in China, thus the labels for negative emotions are often deemed too direct and are less vocally used.

\section{Summary and Limitations}

There are several limitations within the study. One limitation is that the study used survey method to collect data instead of experimental design, thus the nuances of cultural priming and language use cannot be detected and analyzed in the data. The effect of priming often takes place outside conscious awareness. It is hard to ask participants to report the effect of priming in a survey if they are not recognized and registered in the memory in the first place. Future research may wish to employ an experimental design to better detect the priming effect. Secondly, participants were not necessarily equally proficient in English and Chinese, and partners were often not bilingual. More than half of the participants only spoke or mostly spoke English with their partners, and thus it was hard to collect information on their bilingual experience with partner. Future research may wish to collect a more balanced sample of bilingual participants that speak both languages with their partner.

Thirdly, the range of sexual behaviors and experiences was broad in the current study. The inclusion criteria for the study was at least one sexual or romantic relationship, which resulted in the fact that the relationship experiences in the sample ranged from married and monogamous to other types of relationship history. Future researchers are encouraged to narrow the inclusion criteria to one specific relationship status and explore 
it in depth. Fourthly, the reliability for both BII subscales was low (conflict $=.618$;

distance $=.521)$. The reliability of BII conflict scale increased to .858 after modification, whereas the reliability of BII distance did not improve. The reliabilities of BII subscales in other studies were also acceptable at best (alpha $=0.68-0.74$; Benet-Martínez \& Haritatos, 2005; C. Y. Cheng et al., 2006). Future research may seek to develop an updated and more reliable measurement for BII. The BII distance scale was used in analyses despite indications of low reliability, but results should be interpreted with caution.

Additionally, the majority of the sample was heterosexual, and the LGBTQ relationships were minimally represented. According to 2013 NHIS data, $96.6 \%$ of adults in the U.S. identified as heterosexual, 2.3\% identified as gay, lesbian, or bisexual, and $1.1 \%$ identified as "something else" or did not provide an answer (Ward, Dahlhamer, Galinsky, \& Joestl, 2014). In the current sample, 90.5\% identified as heterosexual, 3.2\% identified as gay or lesbian, $4.2 \%$ identified as bisexual, and $1.6 \%$ indicated "other" or "prefer not say". Thus, representation of LGBTQ individuals may have been slightly higher than the general population, but was not large enough to make any meaningful interpretation of results specific for LGBTQ population. Future research may wish to include more sexual minorities in the sample and explore if similar patterns of communication exist for LGBTQ individuals.

Last but not least, the study was focused on only Chinese ethnicity; it is unclear if the conclusion can be extended to other Asian bilinguals. East Asian countries like Korea and Japan traditionally adopted a Neo-Confucian doctrine that espoused more 
conservative values on sexuality and gender roles from China (Brotto et al., 2005; H. Kim et al., 2012; Youn, 2001; Woo, 2016). It is likely that bilinguals with a heritage from Korea and Japan would experience similar conflicting cultural identities and communication patterns. Future researchers are encouraged to investigate how other ethnic bilinguals navigate through various relational contexts.

Overall, language proficiency emerged as the best single predictor of language preference regardless of the contexts or the topics. Men and women reported different patterns of acculturation processes and sexual attitudes. Men experienced more conflict between two cultural identities as their levels of investment in both cultures increased, and such conflict was closely related to conservative sexual attitudes and behaviors. Addressing the conflict of sexual values between two cultures may be especially important for male students. On the other hand, women do not experience the conflict as acculturation levels increase. Both women and men's sexual attitudes and behaviors are consistently associated with language preference, thus they may benefit from practicing sexual communication skills in the language they commonly use for relationship interaction when receiving sexual education. 


\section{REFERENCES}

Benet-Martínez, V., \& Haritatos, J. (2005). Bicultural identity integration (BII): Components and psychosocial antecedents. Journal of Personality, 73, 10151050. doi:10.1111/j.1467-6494.2005.00337.x

Benet-Martínez, V., Leu, J., Lee, F., \& Morris, M. W. (2002). Negotiating biculturalism cultural frame switching in biculturals with oppositional versus compatible cultural identities. Journal of Cross-Cultural Psychology, 33, 492-516. doi: $10.1177 / 0022022102033005005$

Berry, J. W. (2003). Conceptual approaches to acculturation. In K. M. Chun, P. B. Organista, \& G. Marín (Eds.), Acculturation: Advances in theory, measurement, and applied research (pp. 17-37). Washington, DC: American Psychological Association.

Boucher, H. C., \& O'Dowd, M. C. (2011). Language and the bicultural dialectical self. Cultural Diversity and Ethnic Minority Psychology, 17, 211. doi: $10.1037 / \mathrm{a} 0023686$

Brotto, L. A., Chik, H. M., Ryder, A. G., Gorzalka, B. B., \& Seal, B. N. (2005). Acculturation and sexual function in Asian women. Archives of Sexual Behavior, 34, 613-626. doi:10.1007/s10508-005-7909-6

Caron, S. L., Davis, C. M., Halteman, W. A., \& Stickle, M. (1993). Double Standard Scale. In T. D. Fisher, C. M. Davis, W. L. Yarber, \& S. L. Davis (Eds.), Handbook of sexuality-related measures (pp. 182-183). New York, NY: Routledge

Catania, J. A. (2010). Dyadic sexual communication scale. In T. D. Fisher, C. M. Davis, W. L. Yarber, \& S. L. Davis (Eds.), Handbook of sexuality-related measures (pp. 129-131). New York, NY: Routledge

Chen, S. X. (2015). Toward a social psychology of bilingualism and biculturalism. Asian Journal of Social Psychology, 18, 1-11. doi:10.1111/ajsp.12088

Chen, S. X., \& Bond, M. H. (2010). Two languages, two personalities? Examining language effects on the expression of personality in a bilingual context. Personality and Social Psychology Bulletin, 36, 1514-1528. doi: $10.1177 / 0146167210385360$

Chen, S. X., Lam, B. C., Buchtel, E. E., \& Bond, M. H. (2014). The conscientiousness paradox: Cultural mindset shapes competence perception. European Journal of Personality, 28, 425-436. doi:10.1002/per.1923 
Cheng, C. Y., Lee, F., \& Benet-Martínez, V. (2006). Assimilation and contrast effects in cultural frame switching bicultural identity integration and valence of cultural cues. Journal of Cross-Cultural Psychology, 37, 742-760. doi:10.1177/0022022106292081

Cheng, H. (1997). "Holding up half of the sky"? A sociocultural comparison of genderrole portrayals in Chinese and U.S. advertising. International Journal of Advertising, 16, 295-319. doi:10.1111/j.0265-0487.1997.00063.pp.x

Dabhoiwala, F. (2012). The origins of sex: A history of the first sexual revolution. New York, NY: Oxford University Press.

Garlick, S. (2011). A new sexual revolution? Critical theory, pornography, and the Internet. Canadian Review of Sociology/Revue Canadienne de Sociologie,48, 221239. doi:10.1111/j.1755-618X.2011.01264.x

Goldin, P. R. (2016). Women and moral dilemmas in early Chinese narrative. In A. A. Pang-White (Ed.), The Bloomsbury Research Handbook of Chinese Philosophy and Gender (pp. 25-35). New York, NY: Bloomsbury.

Grunbaum, J. A., Lowry, R., Kann, L., \& Pateman, B. (2000). Prevalence of health risk behaviors among Asian American/Pacific Islander high school students. Journal of Adolescent Health, 27, 322-330. doi:10.1016/S1054-139X(00)00093-8

Hoeffel, E. M., Rastogi, S., Kim, M. O., \& Shahid, H. (2012). The Asian population: 2010 (Census 2010 Briefs, No. C2010BR-11). Retrieved from https://www.census.gov/prod/cen2010/briefs/c2010br-11.pdf

Hong, Y. Y., Morris, M.W., Chiu, C. Y., \& Benet- Martínez, V. (2000). Multicultural minds: A dynamic constructivist approach to culture. American Psychologist, 55, 709-720. doi:10.1037//0003-066X.55.7.709

Hurlbert, D. F. (1991). The role of assertiveness in female sexuality: A comparative study between sexually assertive and sexually nonassertive women. Journal of Sex \& Marital Therapy, 17(3), 183-190.

Institute of International Education. (2014). Open doors 2014: International students in the United States and study abroad by American students are at all-time high. Retrieved from http://www.iie.org/Who-We-Are/News-and-Events/PressCenter/Press-Releases/2014/2014-11-17-Open-Doors-Data\#.V5bwIJOAOko

Kao, T. S. A., Loveland-Cherry, C., Guthrie, B., \& Caldwell, C. H. (2011). Acculturation influences on AAPI adolescent-mother interactions and adolescents' sexual initiation. Western Journal of Nursing Research, 33, 712-733. doi:10.1177/0193945910382242 
Kim, H., Edwards, A. B., Sweeney, K. A., \& Wetchler, J. L. (2012). The effects of differentiation and attachment on satisfaction and acculturation in Asian-White American international couple relationships: Assessment with Chinese, South Korean, and Japanese partners in relationships with white American partners in the United States. The American Journal of Family Therapy, 40, 320-335. doi:10.1080/01926187.2011.616409

Kim, J. L., \& Ward, L. M. (2007). Silence speaks volumes: Parental sexual communication among Asian American emerging adults. Journal of Adolescent Research, 22, 3-31. doi:10.1177/0743558406294916

Koo, K. H., Stephens, K. A., Lindgren, K. P., \& George, W. H. (2012). Misogyny, acculturation, and ethnic identity: Relation to rape-supportive attitudes in Asian American college men. Archives of Sexual Behavior, 41, 1005-1014. doi:10.1007/s10508-011-9729-1

Lee, E., \& Mock, M. R. (2005). Asian families: An overview. In M. McGoldrick, J. Giordano, \& N. Garcia-Preto (Eds.), Ethnicity \& family therapy (pp. 269-289). New York, NY: Guilford.

Lee, S. W., Oyserman, D., \& Bond, M. H. (2010). Am I doing better than you? That depends on whether you ask me in English or Chinese: Self-enhancement effects of language as a cultural mindset prime. Journal of Experimental Social Psychology, 46, 785-791. doi:10.1016/j.jesp.2010.04.005

Marian, V., \& Neisser, U. (2000). Language-dependent recall of autobiographical memories. Journal of Experimental Psychology: General, 129, 361-368. doi:10.1037//0096-3445.129.3.361

Masters, W. H., \& Johnson, V. E. (1976). Principles of the new sex therapy [abstract]. The American Journal of Psychiatry, 133, 548-554. Retrieved from http://psycnet.apa.org/psycinfo/1976-21000-001

Matsumoto, D., Anguas-Wong, A. M., \& Martinez, E. (2008). Priming effects of language on emotion judgments in Spanish-English bilinguals. Journal of CrossCultural Psychology, 39, 335-342. doi:10.1177/0022022108315489

McNair, B. (2002). Striptease culture: Sex, media and the democratization of desire. New York, NY: Routledge.

Meston, C. M., \& Ahrold, T. (2010). Ethnic, gender, and acculturation influences on sexual behaviors. Archives of Sexual Behavior, 39(1), 179-189.

Meston, C. M., Trapnell, P. D., \& Gorzalka, B. B. (1998). Ethnic, gender, and length-ofresidency influences on sexual knowledge and attitudes. Journal of Sex Research, 35, 176-188. doi:10.1080/00224499809551931 
Morton, H., \& Gorzalka, B. B. (2013). Cognitive aspects of sexual functioning: Differences between East Asian-Canadian and Euro-Canadian women. Archives of Sexual Behavior, 42, 1615-1625. doi:10.1007/s10508-013-0180-3

Oyserman, D., \& Lee, S. W. (2008). Does culture influence what and how we think? Effects of priming individualism and collectivism. Psychological Bulletin, 134, 311. doi:10.1037/0033-2909.134.2.311

Pew Research Center. (2013). The rise of Asian Americans. Retrieved from http://www.pewsocialtrends.org/2012/06/19/the-rise-of-asian-americans/

Robinson, I., Ziss, K., Ganza, B., \& Katz, S. (1991). Twenty years of the sexual revolution, 1965-1985: An update. Journal of Marriage and Family, 53, 216-220. Retrieved from http://www.jstor.org/stable/353145

Ruan, F. F. (1991). Sex in China: Studies in sexology in Chinese culture. New York, NY: Springer.

Ryder, A. G., Alden, L. E., \& Paulhus, D. L. (2000). Is acculturation unidimensional or bidimensional? A head-to-head comparison in the prediction of personality, selfidentity, and adjustment. Journal of Personality and Social Psychology, 79, 4965. doi:10.1037//0022-3514.79.1.49

Tong, Y. (2013). Acculturation, gender disparity, and the sexual behavior of Asian American youth. Journal of Sex Research, 50, 560-573. doi:10.1080/ 00224499.2012 .668976

Trafimow, D., Silverman, E. S., Fan, R. M. T., \& Law, J. S. F. (1997). The effects of language and priming on the relative accessibility of the private self and the collective self. Journal of Cross-Cultural Psychology, 28, 107-123. doi:10.1177/0022022197281007

U.S. Census Bureau. (2014). 2010-2014 American Community Survey 5-Year Estimates. Retrieved from http://factfinder.census.gov/faces/tableservices/jsf/pages/ productview.xhtml? src $=$ bkmk

Verkuyten, M., \& Pouliasi, K. (2006). Biculturalism and group identification: the mediating role of identification in cultural frame switching. Journal of CrossCultural Psychology, 37, 312-326. doi:10.1177/0022022106286926

Wang, E. H. (2016). Moral reasoning: The female way and the Xunzian Way. In A. A. Pang-White (Eds.), The Bloomsbury research handbook of Chinese philosophy and gender (pp. 141-156). New York, NY: Bloomsbury. 
Ward, B. W., Dahlhamer, J. M., Galinsky, A. M., \& Joestl, S. S. (2014). Sexual orientation and health among U.S. adults: National Health Interview Survey, 2013. National Health Statistics Reports, 77, 1-11. Retrieved from https://stacks.cdc.gov/view/cdc/24087

Woo, T. T. (2016). Discourse on women from the classical period to the Song: An Integrated Approach. In A. A. Pang-White (Eds.), The Bloomsbury research handbook of Chinese philosophy and gender (pp. 37-68). New York, NY: Bloomsbury.

Woo, J. S., \& Brotto, L. A. (2008). Age of first sexual intercourse and acculturation: Effects on adult sexual responding. The Journal of Sexual Medicine, 5, 571-582. doi:10.1111/j.1743-6109.2007.00740.x

Woo, J. S., Brotto, L. A., \& Gorzalka, B. B. (2011). The role of sex guilt in the relationship between culture and women's sexual desire. Archives of Sexual Behavior, 40, 385-394. doi:10.1007/s10508-010-9609-0

Yan, E., Wu, A. M. S., Ho, P., \& Pearson, V. (2011). Older Chinese men and women's experiences and understanding of sexuality. Culture, Health \& Sexuality, 13(9), 983-999.

Youn, G. (2001). Perceptions of peer sexual activities in Korean adolescents. Journal of Sex Research, 38, 352-360. doi:10.1080/00224490109552106

Zhang, L., Li, X., \& Shah, I. H. (2007). Where do Chinese adolescents obtain knowledge of sex? Implications for sex education in China. Health Education, 107(4), 351363.

Zhang, S., Morris, M. W., Cheng, C. Y., \& Yap, A. J. (2013). Heritage-culture images disrupt immigrants' second-language processing through triggering first-language interference. Proceedings of the National Academy of Sciences, 110, 1127211277. doi: 10.1073/pnas. 1304435110 
APPENDICES 
Appendix A

Informed Consent 


\section{Informed Consent}

\section{Acculturation and Language use in Intimate and Sexual Relationships among Chinese Bilinguals}

\section{Introduction}

You are invited to participate in a research study conducted by Renee Galliher, professor, and Tianyi Xie, a graduate student in the Department of Psychology at Utah State University. The purpose of this research is to understand Chinese bilinguals' acculturation and language preferences (i.e., native language vs. English) in romantic and sexual experiences.

This form includes detailed information on the research to help you decide whether to participate in this study. Please read it carefully and ask any questions you have before you agree to participate.

\section{Procedures}

Your participation will involve completing an online survey assessing your attitudes about your heritage culture and U.S. culture, intimate interaction with your partner(s), and language preferences in various situations. Participation in the survey is anonymous and is expected to take 25 minutes. We anticipate that 170 people will participate in this research study.

\section{Risks}

This is a minimal risk research study. That means that the risks of participating are no more likely or serious than those you encounter in everyday activities. There is some risk that your identity as research participants will be disclosed to others, which can be minimized if you complete the survey in a private location and close the browser upon completion. No identifying information will be collected in the survey. There is also the possibility that you may experience some discomfort answering questions about your intimate experiences with your partner(s). You may refuse to answer questions or discontinue the participation at any time. If you have a negative research-related experience or are injured in any way during your participation, please contact the principal investigator of this study right away at (435)797-3391 or Renee.Galliher@usu.edu.

\section{Benefits}

There is no direct benefit to you for participating in this research study. More broadly, this study will help the researchers learn more about Chinese bilinguals' intimate relationships and may help health care providers and educators to provide better interventions and sexual education.

\section{Confidentiality}

The information you provide as part of this study will be delivered to the researchers in anonymous form. Your responses will be collected by Qualtrics and delivered to the researchers with no identifying information. There will be no way to link your responses to your name. Deidentified survey responses will be kept indefinitely.

The research team works to ensure confidentiality to the degree permitted by technology. It is possible, although unlikely, that unauthorized individuals could gain access to your responses because you are responding online. However, your participation in this online survey involves risks similar to a person's everyday use of the Internet. 


\section{Voluntary Participation, Withdrawal [and Costs]}

Your participation in this research is completely voluntary. If you agree to participate now and change your mind later, you may withdraw at any time by simply exiting the survey.

\section{Compensation}

For your participation in this research study, you will receive compensation from Qualtrics in accordance with your agreement with them.

\section{IRB Review}

The Institutional Review Board (IRB) for the protection of human research participants at Utah State University has reviewed and approved this study. If you have questions about the research study itself, please contact the Principal Investigator at (435)797-3391 or Renee.Galliher@usu.edu or the student investigator at Tianyi.Xie@aggiemail.usu.edu. If you have questions about your rights or would simply like to speak with someone other than the research team about questions or concerns, please contact the IRB Director at (435) 797-0567 or irb@usu.edu.

Renee V. Galliher, $\mathrm{PhD} \quad$ Tianyi Xie

Renee V. Galliher, PhD Tianyi Xie

Principal Investigator Student Investigator

(435) 797-3391; Renee.Galliher@usu.edu

Tianyi.Xie@aggiemail.usu.edu

\section{Informed Consent}

By clicking on the link below, you agree to participate in this study. You indicate that you understand the risks and benefits of participation, and that you know what you will be asked to do. You also agree that you have asked any questions you might have, and are clear on how to stop your participation in the study if you choose to do so. Please be sure to retain a copy of this form for your records. 
Appendix B

Measures 
Screening questions:

1. Are you between 18 and 30 years of age?

Yes No

2. Is your ethnic background from the greater China region (Mainland China, Hong Kong, Taiwan, or Macau)?

Yes No

3. Can you speak both English and your heritage language?

Yes No

4. Have you been in at least one romantic or sexual relationship?

Yes No

Demographic information

1. What is/are your race(s) and/or ethnicity(ies)? (mark all that apply)

Greater Chinese descent
Pacific Islander/Hawaiian Native
African Descent/Black American
West Asian / Middle Eastern
Other: (describe)

2. What is your self-identified heritage culture from the greater China region?

Mainland China/Mainland Chinese
Macau

Hispanic/Latino

European descent/White American

Native American/Alaskan Native

Other Asian Descent

3. Time in U.S _ Years

Months

4. In which State are you currently living?

5. In which State have you lived the longest?

6. Time in heritage country __ Years Months 
7. What is your age in years?

8. What is your gender?

Female __ Male other (please specify)

9. Religious Affiliation

$1=$ Atheist $2=$ Agnostic $3=\operatorname{Islam} 4=$ Buddhism $5=$ Hinduism $6=$ Daoism $7=$ Judaism $8=$ Christian $9=$ Other

10. What is your current relationship status?

Single not dating

Single and dating

Dating monogamously

Cohabiting

Married

Divorced, separated, or widowed

11. Length of longest relationship:

Years months

12. Length of current relationship (if applicable):

Years months

13. Ethnicity(ies) of current or most recent romantic partner (mark all that apply):

Native American/Alaskan Native

Pacific Islander/Hawaiian Native

African Descent/Black American

Other Eastern Asian descent

South Asian Descent
Hispanic/Latino

European descent/White American

Greater Chinese descent

West Asian / Middle Eastern

Other: (describe)

14. If your current or most recent romantic partner is from the greater China region, what is his/her heritage culture?

$\begin{array}{ll}\text { Mainland China/Mainland Chinese } & \text { Hong Kong } \\ \text { _ Macau } & \text { Taiwan }\end{array}$

15. Sexual orientation:

Heterosexual

Lesbian/gay

Bisexual

Other (please specify)

16. Number of romantic relationships: 
17. Number of total sexual partners (past and current):

18. Ethnicity of partners in continuum:

\begin{tabular}{|c|c|c|c|c|c|c|c|c|}
\hline $\begin{array}{c}\text { Outside } \\
\text { of my } \\
\text { thnicity } \\
\text { only }\end{array}$ & & & Equal & & & & $\begin{array}{c}\text { My } \\
\text { ethnicity } \\
\text { only }\end{array}$ \\
\hline 1 & 2 & 3 & 4 & 5 & 6 & 7 & 8 & 9 \\
\hline
\end{tabular}

\section{Vancouver Index of Acculturation (VIA)}

Please circle one of the numbers to the right of each question to indicate your degree of agreement or disagreement.

Many of these questions will refer to your heritage culture, meaning the original culture of your family (other than American). It may be the culture of your birth, the culture in which you have been raised, or any culture in your family background. If there are several, pick the one that has influenced you most (e.g. Irish, Chinese, Mexican, African). If you do not feel that you have been influenced by any other culture, please name a culture that influenced previous generations of your family. Your heritage culture (other than American) is:

\begin{tabular}{|c|c|c|c|c|c|c|c|c|c|}
\hline \multirow[b]{2}{*}{ 1. I often participate in my heritage cultural traditions. } & \multicolumn{3}{|c|}{$\begin{array}{l}\text { Strongly } \\
\text { Disagree }\end{array}$} & \multirow[b]{2}{*}{4} & \multirow[b]{2}{*}{5} & \multirow[b]{2}{*}{6} & \multicolumn{3}{|c|}{$\begin{array}{l}\text { Strongly } \\
\text { Agree }\end{array}$} \\
\hline & 1 & 2 & 3 & & & & 7 & 8 & 9 \\
\hline 2. I often participate in mainstream American cultural traditions. & 1 & 2 & 3 & 4 & 5 & 6 & 7 & 8 & 9 \\
\hline 3. I would be willing to marry a person from my heritage culture. & 1 & 2 & 3 & 4 & 5 & 6 & 7 & 8 & 9 \\
\hline 4. I would be willing to marry a white American person. & 1 & 2 & 3 & 4 & 5 & 6 & 7 & 8 & 9 \\
\hline $\begin{array}{l}\text { 5. I enjoy social activities with people from the same heritage } \\
\text { culture as myself. }\end{array}$ & 1 & 2 & 3 & 4 & 5 & 6 & 7 & 8 & 9 \\
\hline 6. I enjoy social activities with typical American people. & 1 & 2 & 3 & 4 & 5 & 6 & 7 & 8 & 9 \\
\hline $\begin{array}{l}\text { 7. I am comfortable interacting with people of the same heritage } \\
\text { culture as myself. }\end{array}$ & 1 & 2 & 3 & 4 & 5 & 6 & 7 & 8 & 9 \\
\hline 8. I am comfortable interacting with typical American people. & 1 & 2 & 3 & 4 & 5 & 6 & 7 & 8 & 9 \\
\hline $\begin{array}{l}\text { 9. I enjoy entertainment (e.g. movies, music) from my heritage } \\
\text { culture. }\end{array}$ & 1 & 2 & 3 & 4 & 5 & 6 & 7 & 8 & 9 \\
\hline
\end{tabular}




\begin{tabular}{|c|c|c|c|c|c|c|c|c|c|}
\hline 10. I enjoy American entertainment (e.g. movies, music). & 1 & 2 & 3 & 4 & 5 & 6 & 7 & 8 & 9 \\
\hline 11. I often behave in ways that are typical of my heritage culture. & 1 & 2 & 3 & 4 & 5 & 6 & 7 & 8 & 9 \\
\hline 12. I often behave in ways that are typically American. & 1 & 2 & 3 & 4 & 5 & 6 & 7 & 8 & 9 \\
\hline $\begin{array}{l}\text { 13. It is important for me to maintain or develop the practices of } \\
\text { my heritage culture. }\end{array}$ & 1 & 2 & 3 & 4 & 5 & 6 & 7 & 8 & 9 \\
\hline $\begin{array}{l}\text { 14. It is important for me to maintain or develop American } \\
\text { cultural practices. }\end{array}$ & 1 & 2 & 3 & 4 & 5 & 6 & 7 & 8 & 9 \\
\hline 15. I believe in the values of my heritage culture. & 1 & 2 & 3 & 4 & 5 & 6 & 7 & 8 & 9 \\
\hline 16. I believe in mainstream American values. & 1 & 2 & 3 & 4 & 5 & 6 & 7 & 8 & 9 \\
\hline 17. I enjoy the jokes and humor of my heritage culture. & 1 & 2 & 3 & 4 & 5 & 6 & 7 & 8 & 9 \\
\hline 18. I enjoy white American jokes and humor. & 1 & 2 & 3 & 4 & 5 & 6 & 7 & 8 & 9 \\
\hline 19. I am interested in having friends from my heritage culture. & 1 & 2 & 3 & 4 & 5 & 6 & 7 & 8 & 9 \\
\hline 20. I am interested in having white American friends. & 1 & 2 & 3 & 4 & 5 & 6 & 7 & 8 & 9 \\
\hline
\end{tabular}

\section{Bicultural Identity Integration Scale (BIIS-1)}

\begin{tabular}{|c|c|c|c|c|c|c|c|c|c|}
\hline & \multicolumn{3}{|c|}{$\begin{array}{l}\text { Strongly } \\
\text { Disagree }\end{array}$} & \multirow[b]{2}{*}{4} & \multirow[b]{2}{*}{5} & \multirow[b]{2}{*}{6} & \multicolumn{3}{|c|}{$\begin{array}{l}\text { Strongly } \\
\text { Agree }\end{array}$} \\
\hline 1. I am simply an Asian who lives in North America & 1 & 2 & 3 & & & & 7 & 8 & 9 \\
\hline 2. I keep Asian and American cultures separate & 1 & 2 & 3 & 4 & 5 & 6 & 7 & 8 & 9 \\
\hline 3. I feel Asian American & 1 & 2 & 3 & 4 & 5 & 6 & 7 & 8 & 9 \\
\hline 4. I feel part of a combined culture & 1 & 2 & 3 & 4 & 5 & 6 & 7 & 8 & 9 \\
\hline $\begin{array}{l}\text { 5. I am conflicted between the American and Asian ways of } \\
\text { doing things }\end{array}$ & 1 & 2 & 3 & 4 & 5 & 6 & 7 & 8 & 9 \\
\hline 6. I feel like someone moving between two cultures & 1 & 2 & 3 & 4 & 5 & 6 & 7 & 8 & 9 \\
\hline 7. I feel caught between the Asian and American cultures & 1 & 2 & 3 & 4 & 5 & 6 & 7 & 8 & 9 \\
\hline $\begin{array}{l}\text { 8. I don't feel trapped between the Asian and } \\
\text { American cultures }\end{array}$ & 1 & 2 & 3 & 4 & 5 & 6 & 7 & 8 & 9 \\
\hline
\end{tabular}


Hurlbert Index of Sexual Assertiveness

This inventory is designed to measure the degree of sexual assertiveness you have in the sexual relationship with your partner. This is not a test, so there are no right or wrong answers. Please answer each item as accurately as you can.

\begin{tabular}{|c|c|c|c|c|c|}
\hline & $\begin{array}{l}\text { All of } \\
\text { the time }\end{array}$ & $\begin{array}{l}\text { Most of } \\
\text { the time }\end{array}$ & $\begin{array}{l}\text { Some of } \\
\text { the time }\end{array}$ & Rarely & Never \\
\hline 1. I feel uncomfortable talking during sex & 0 & 1 & 2 & 3 & 4 \\
\hline 2. I feel that I am shy when it comes to sex & 0 & 1 & 2 & 3 & 4 \\
\hline $\begin{array}{l}\text { 3. I approach my partner for sex when I desire } \\
\text { it }\end{array}$ & 0 & 1 & 2 & 3 & 4 \\
\hline $\begin{array}{l}\text { 4. I think I am open with my partner about my } \\
\text { sexual needs }\end{array}$ & 0 & 1 & 2 & 3 & 4 \\
\hline $\begin{array}{l}\text { 5. I enjoy sharing my sexual desires to my } \\
\text { partner }\end{array}$ & 0 & 1 & 2 & 3 & 4 \\
\hline $\begin{array}{l}\text { 6. I feel uncomfortable talking to my friends } \\
\text { about sex. }\end{array}$ & 0 & 1 & 2 & 3 & 4 \\
\hline $\begin{array}{l}\text { 7. I communicate my sexual desires to my } \\
\text { partner }\end{array}$ & 0 & 1 & 2 & 3 & 4 \\
\hline $\begin{array}{l}\text { 8. It is difficult for me to touch myself during } \\
\text { sex. }\end{array}$ & 0 & 1 & 2 & 3 & 4 \\
\hline $\begin{array}{l}\text { 9. It is hard for me to say no even when I do } \\
\text { not want sex. }\end{array}$ & 0 & 1 & 2 & 3 & 4 \\
\hline $\begin{array}{l}\text { 10. I am reluctant to describe myself as a } \\
\text { sexual person. }\end{array}$ & 0 & 1 & 2 & 3 & 4 \\
\hline $\begin{array}{l}\text { 11. I feel uncomfortable telling my partner } \\
\text { what feels good. }\end{array}$ & 0 & 1 & 2 & 3 & 4 \\
\hline 12. I speak up for my sexual feelings. & 0 & 1 & 2 & 3 & 4 \\
\hline $\begin{array}{l}\text { 13. I am reluctant to insist that my partner } \\
\text { satisfy me. }\end{array}$ & 0 & 1 & 2 & 3 & 4 \\
\hline $\begin{array}{l}\text { 14. I find myself having sex when I do not } \\
\text { really want it. }\end{array}$ & 0 & 1 & 2 & 3 & 4 \\
\hline $\begin{array}{l}\text { 15. When a technique does not feel good, I tell } \\
\text { my partner. }\end{array}$ & 0 & 1 & 2 & 3 & 4 \\
\hline $\begin{array}{l}\text { 16. I feel comfortable giving sexual praise to } \\
\text { my partner. }\end{array}$ & 0 & 1 & 2 & 3 & 4 \\
\hline $\begin{array}{l}\text { 17. It is easy for me to discuss sex with my } \\
\text { partner. }\end{array}$ & 0 & 1 & 2 & 3 & 4 \\
\hline
\end{tabular}




\begin{tabular}{|l|c|c|c|c|c|}
\hline & $\begin{array}{c}\text { All of } \\
\text { the time }\end{array}$ & $\begin{array}{c}\text { Most of } \\
\text { the time }\end{array}$ & $\begin{array}{c}\text { Some of } \\
\text { the time }\end{array}$ & Rarely & Never \\
\hline $\begin{array}{l}\text { 18. I feel comfortable initiating sex with my } \\
\text { partner. }\end{array}$ & 0 & 1 & 2 & 3 & 4 \\
\hline $\begin{array}{l}\text { 19. I find myself doing sexual things that I do } \\
\text { not like. }\end{array}$ & 0 & 1 & 2 & 3 & 4 \\
\hline $\begin{array}{l}\text { 20. Pleasing my partner is more important than } \\
\text { my pleasure. }\end{array}$ & 0 & 1 & 2 & 3 & 4 \\
\hline $\begin{array}{l}\text { 21. I feel comfortable telling my partner how } \\
\text { to touch me }\end{array}$ & 0 & 1 & 2 & 3 & 4 \\
\hline $\begin{array}{l}\text { 22. I enjoy masturbating myself to orgasm. } \\
\text { 23. If something feels good, I insist on doing it } \\
\text { again. }\end{array}$ & 0 & 1 & 2 & 3 & 4 \\
\hline $\begin{array}{l}\text { 24. It is hard for me to be honest about my } \\
\text { sexual feelings. }\end{array}$ & 0 & 1 & 2 & 3 & 4 \\
\hline 25. I try to avoid discussing the subject of sex. & 0 & 1 & 2 & 3 & 4 \\
\hline
\end{tabular}


Double Standard Scale

Please circle your response to the following questions regarding your attitude about the sex roles of men and women. Please keep in mind that there are no right or wrong answers. Please answer honestly.

\begin{tabular}{|l|c|c|c|c|c|}
\hline & $\begin{array}{c}\text { Strongly } \\
\text { agree }\end{array}$ & Agree & Undecided & Disagree & $\begin{array}{c}\text { Strongly } \\
\text { Disagree }\end{array}$ \\
\hline $\begin{array}{l}\text { 1. It is expected that a woman be less } \\
\text { sexually experienced than her partner. }\end{array}$ & 1 & 2 & 3 & 4 & 5 \\
\hline $\begin{array}{l}\text { 2. A woman who is sexually active is } \\
\text { less likely to be considered a } \\
\text { desirable partner. }\end{array}$ & 1 & 2 & 3 & 4 & 5 \\
\hline $\begin{array}{l}\text { 3. A woman should never appear to } \\
\text { be prepared for a sexual encounter. }\end{array}$ & 1 & 2 & 3 & 4 & 5 \\
\hline $\begin{array}{l}\text { 4. It is important that the men be } \\
\text { sexually experienced so as to teach } \\
\text { the women. }\end{array}$ & 1 & 2 & 3 & 4 & 5 \\
\hline $\begin{array}{l}\text { 5. A "good" woman would never } \\
\text { have a one-night stand, but it is } \\
\text { expected of a man. }\end{array}$ & 1 & 2 & 3 & 4 & 5 \\
\hline $\begin{array}{l}\text { 6. It is important for a man to have } \\
\text { multiple sexual experiences in order } \\
\text { to gain experience. }\end{array}$ & 1 & 2 & 3 & 4 & 5 \\
\hline $\begin{array}{l}\text { 7. In sex the man should take the } \\
\text { dominant role and the woman should } \\
\text { assume the passive role. }\end{array}$ & 1 & 2 & 3 & 4 & 5 \\
\hline $\begin{array}{l}\text { 8. It is acceptable for a woman to } \\
\text { carry condoms. }\end{array}$ & 1 & 2 & 3 & 4 & 5 \\
\hline $\begin{array}{l}\text { 9. It is worse for a woman to sleep } \\
\text { around than it is for men. }\end{array}$ & 1 & 2 & 3 & 4 & 5 \\
\hline \begin{tabular}{l} 
10. It is up to the man to initiate sex \\
\hline
\end{tabular} & 1 & 2 & 3 & 4 & 5 \\
\hline
\end{tabular}




\section{Dyadic Sexual Communication Scale}

Please indicate how much you agree or disagree on the following statements about your primary sexual partner.

\begin{tabular}{|c|c|c|c|c|c|c|}
\hline & $\begin{array}{c}\text { Strongly } \\
\text { agree }\end{array}$ & & & & & $\begin{array}{l}\text { Strongly } \\
\text { Disagree }\end{array}$ \\
\hline $\begin{array}{l}\text { 1. My partner rarely responds } \\
\text { when I want to talk about our } \\
\text { sex life. }\end{array}$ & 1 & 2 & 3 & 4 & 5 & 6 \\
\hline $\begin{array}{l}\text { 2. Some sexual matters are too } \\
\text { upsetting to discuss with my } \\
\text { sexual partner. }\end{array}$ & 1 & 2 & 3 & 4 & 5 & 6 \\
\hline $\begin{array}{l}\text { 3. There are sexual issues or } \\
\text { problems in our sexual } \\
\text { relationship that we have } \\
\text { never discussed. }\end{array}$ & 1 & 2 & 3 & 4 & 5 & 6 \\
\hline $\begin{array}{l}\text { 4. My partner and I never } \\
\text { seem to resolve our } \\
\text { disagreements about sexual } \\
\text { matters. }\end{array}$ & 1 & 2 & 3 & 4 & 5 & 6 \\
\hline $\begin{array}{l}\text { 5. Whenever my partner and I } \\
\text { talk about sex, I feel like she } \\
\text { or he is lecturing me. }\end{array}$ & 1 & 2 & 3 & 4 & 5 & 6 \\
\hline $\begin{array}{l}\text { 6. My partner often complains } \\
\text { that I am not very clear about } \\
\text { what I want sexually. }\end{array}$ & 1 & 2 & 3 & 4 & 5 & 6 \\
\hline $\begin{array}{l}\text { 7. My partner and I have never } \\
\text { had a heart to heart talk about } \\
\text { out sex life together. }\end{array}$ & 1 & 2 & 3 & 4 & 5 & 6 \\
\hline $\begin{array}{l}\text { 8. My partner has no difficulty } \\
\text { in talking to me about his or } \\
\text { her sexual feelings and } \\
\text { desires. }\end{array}$ & 1 & 2 & 3 & 4 & 5 & 6 \\
\hline $\begin{array}{l}\text { 9.Even when angry with me, } \\
\text { my partner is able to } \\
\text { appreciate my view on } \\
\text { sexuality. }\end{array}$ & 1 & 2 & 3 & 4 & 5 & 6 \\
\hline $\begin{array}{l}\text { 10. Talking about sex is a } \\
\text { satisfying experience for both } \\
\text { of us. }\end{array}$ & 1 & 2 & 3 & 4 & 5 & 6 \\
\hline $\begin{array}{l}\text { 11. My partner and I can } \\
\text { usually talk calmly about our } \\
\text { sex life. }\end{array}$ & 1 & 2 & 3 & 4 & 5 & 6 \\
\hline $\begin{array}{l}\text { 12. I have little difficulty in } \\
\text { telling my partner what I do or } \\
\text { don't do sexually. }\end{array}$ & 1 & 2 & 3 & 4 & 5 & 6 \\
\hline $\begin{array}{l}\text { 13. I seldom feel embarrassed } \\
\text { when talking about the details } \\
\text { of our sex life with my } \\
\text { partner. }\end{array}$ & 1 & 2 & 3 & 4 & 5 & 6 \\
\hline
\end{tabular}


Sexual experiences:

Answer the following questions based on your experience with your primary partner(s):

\begin{tabular}{|c|c|c|c|c|c|c|c|c|c|}
\hline & None & & & & & & & & A lot \\
\hline $\begin{array}{l}\text { 1. How much sexual } \\
\text { experience do you think } \\
\text { you have? }\end{array}$ & 1 & 2 & 3 & 4 & 5 & 6 & 7 & 8 & 9 \\
\hline $\begin{array}{l}\text { 2. How much sexual } \\
\text { experience do you think } \\
\text { your partner(s) has? }\end{array}$ & 1 & 2 & 3 & 4 & 5 & 6 & 7 & 8 & 9 \\
\hline $\begin{array}{l}\text { 3. How often do you } \\
\text { and your partner have } \\
\text { sex? }\end{array}$ & 1 & 2 & 3 & 4 & 5 & 6 & 7 & 8 & 9 \\
\hline $\begin{array}{l}\text { 4. How often do you } \\
\text { and your partner discuss } \\
\text { sexual topics? }\end{array}$ & 1 & 2 & 3 & 4 & 5 & 6 & 7 & 8 & 9 \\
\hline $\begin{array}{l}\text { 5. How often do you } \\
\text { and your partner have } \\
\text { conflict on sex? }\end{array}$ & 1 & 2 & 3 & 4 & 5 & 6 & 7 & 8 & 9 \\
\hline \multirow[t]{2}{*}{$\begin{array}{l}\text { 6. How often do you } \\
\text { engage in risky sexual } \\
\text { behaviors? }\end{array}$} & 1 & 2 & 3 & 4 & 5 & 6 & 7 & 8 & 9 \\
\hline & $\mathrm{Me}$ & & & & Equal & & & & $\begin{array}{c}\text { My } \\
\text { partner }\end{array}$ \\
\hline $\begin{array}{l}\text { 7. Who usually initiates } \\
\text { sex? }\end{array}$ & 1 & 2 & 3 & 4 & 5 & 6 & 7 & 8 & 9 \\
\hline $\begin{array}{l}\text { 8. Who usually ends } \\
\text { sex? }\end{array}$ & 1 & 2 & 3 & 4 & 5 & 6 & 7 & 8 & 9 \\
\hline $\begin{array}{l}\text { 9. Who usually decides } \\
\text { the frequency of sex? }\end{array}$ & 1 & 2 & 3 & 4 & 5 & 6 & 7 & 8 & 9 \\
\hline $\begin{array}{l}10 . \text { Who usually is } \\
\text { more satisfied with sex? }\end{array}$ & 1 & 2 & 3 & 4 & 5 & 6 & 7 & 8 & 9 \\
\hline
\end{tabular}




\section{Language Fluency}

How fluent are you in English?

\begin{tabular}{|c|c|c|c|c|c|c|c|c|}
\hline $\begin{array}{c}\text { Very } \\
\text { limited }\end{array}$ & & & & $\begin{array}{c}\text { Somewhat } \\
\text { fluent }\end{array}$ & & & & Very fluent \\
\hline 1 & 2 & 3 & 4 & 5 & 6 & 7 & 8 & 9 \\
\hline
\end{tabular}

How fluent are you in your heritage language?

\begin{tabular}{|c|c|c|c|c|c|c|c|c|}
\hline $\begin{array}{c}\text { Very } \\
\text { limited }\end{array}$ & & & & $\begin{array}{c}\text { Somewhat } \\
\text { fluent }\end{array}$ & & & & Very fluent \\
\hline 1 & 2 & 3 & 4 & 5 & 6 & 7 & 8 & 9 \\
\hline
\end{tabular}

\section{Language preferences}

\begin{tabular}{|c|c|c|c|c|c|c|c|c|c|}
\hline $\begin{array}{l}\text { Which language do you prefer in the } \\
\text { following situations? }\end{array}$ & $\begin{array}{l}\text { English } \\
\text { only }\end{array}$ & & & & $\begin{array}{l}\text { Equal } \\
\text { use }\end{array}$ & & & & $\begin{array}{c}\text { Heritage } \\
\text { language } \\
\text { only }\end{array}$ \\
\hline 1. Read & 1 & 2 & 3 & 4 & 5 & 6 & 7 & 8 & 9 \\
\hline 2. Write & 1 & 2 & 3 & 4 & 5 & 6 & 7 & 8 & 9 \\
\hline 3. Speak & 1 & 2 & 3 & 4 & 5 & 6 & 7 & 8 & 9 \\
\hline 4. With family members & 1 & 2 & 3 & 4 & 5 & 6 & 7 & 8 & 9 \\
\hline 5. With friends & 1 & 2 & 3 & 4 & 5 & 6 & 7 & 8 & 9 \\
\hline 6. At school & 1 & 2 & 3 & 4 & 5 & 6 & 7 & 8 & 9 \\
\hline 7. With current romantic partner(s) & 1 & 2 & 3 & 4 & 5 & 6 & 7 & 8 & 9 \\
\hline 8. With past romantic partner(s) & 1 & 2 & 3 & 4 & 5 & 6 & 7 & 8 & 9 \\
\hline
\end{tabular}




\begin{tabular}{|l|c|c|c|c|c|c|c|c|c|}
\hline $\begin{array}{l}\text { Which language do you prefer with the } \\
\text { following topics? }\end{array}$ & $\begin{array}{c}\text { English } \\
\text { only }\end{array}$ & & & $\begin{array}{c}\text { Equal } \\
\text { use }\end{array}$ & & & $\begin{array}{c}\text { Heritage } \\
\text { language } \\
\text { only }\end{array}$ \\
\hline 1. Academic/vocational topics & 1 & 2 & 3 & 4 & 5 & 6 & 7 & 8 & 9 \\
\hline 2. Negative emotional topics & 1 & 2 & 3 & 4 & 5 & 6 & 7 & 8 & 9 \\
\hline 3. Positive emotional topics & 1 & 2 & 3 & 4 & 5 & 6 & 7 & 8 & 9 \\
\hline 4. Relationship topics & 1 & 2 & 3 & 4 & 5 & 6 & 7 & 8 & 9 \\
\hline 5. Sexuality related topics & 1 & 2 & 3 & 4 & 5 & 6 & 7 & 8 & 9 \\
\hline & 1 & 2 & 3 & 4 & 5 & 6 & 7 & 8 & 9 \\
\hline
\end{tabular}

\begin{tabular}{|l|c|c|c|c|c|c|c|c|c|}
\hline $\begin{array}{l}\text { Which language do you prefer with the } \\
\text { following purposes? }\end{array}$ & $\begin{array}{c}\text { English } \\
\text { only }\end{array}$ & & & $\begin{array}{c}\text { Equal } \\
\text { use }\end{array}$ & & & $\begin{array}{c}\text { Heritage } \\
\text { language } \\
\text { only }\end{array}$ \\
\hline 1. Asserting & 1 & 2 & 3 & 4 & 5 & 6 & 7 & 8 & 9 \\
\hline 2. Setting boundaries & 1 & 2 & 3 & 4 & 5 & 6 & 7 & 8 & 9 \\
\hline 3. Negotiating differences & 1 & 2 & 3 & 4 & 5 & 6 & 7 & 8 & 9 \\
\hline 4. Compromising & 1 & 2 & 3 & 4 & 5 & 6 & 7 & 8 & 9 \\
\hline 5. Connecting & 1 & 2 & 3 & 4 & 5 & 6 & 7 & 8 & 9 \\
\hline 6. Resolving conflicts & 1 & 2 & 3 & 4 & 5 & 6 & 7 & 8 & 9 \\
\hline
\end{tabular}


Open-ended questions:

1. Romantic partners negotiate many aspects of their relationships, and bilingual individuals communicate with their partners in both languages. Please provide examples of the ways you use your heritage language or English for the following purposes. Please note any differences you observe in how these topics are discussed in English versus your heritage language. If you describe terms or phrases in your heritage language, please provide a literal English translation and note any limitations of translating the phrase to English.

Expressing positive emotions:

Expressing negative emotions:

Making decisions as a couple (e.g., finances, relationship progression, shared activities):

Initiate, negotiate, or end sexual activities:

2. In your romantic relationships or interactions, for which topics do you prefer to use English?

3. In your romantic relationship or interactions, for which topics do you prefer to use your heritage language? 